\title{
Groundwater flow characterization of an ophiolitic hard-rock aquifer from cross-borehole multi-level hydraulic experiments
}

\author{
Gérard Lods ${ }^{\mathrm{a}}$, Delphine Roubinet ${ }^{\mathrm{a}, *}$, Jürg M. Matter ${ }^{\mathrm{b}}$, Richard Leprovost ${ }^{\mathrm{a}}$, \\ Philippe Gouze ${ }^{\mathrm{a}}$, Oman Drilling Project Science Team \\ ${ }^{a}$ Geosciences Montpellier, University of Montpellier, CNRS, Montpellier, France \\ ${ }^{b}$ Ocean and Earth Science, National Oceanography Centre Southampton, University of \\ Southampton, United Kingdom
}

\begin{abstract}
Ophiolitic formations play a critical role in the groundwater resource of numerous countries and areas. Previous studies show that the structural heterogeneities of these rocks, coming from the presence of both different lithological units and multi-scale discontinuities, result in complex hydrogeological features that are not well characterized yet. In particular, there is a need for understanding how these heterogeneities impact the hydrodynamic properties of ophiolitic aquifers and the highly variable chemical composition of the water. To this end, we conduct various kinds of pumping experiments between two boreholes $15 \mathrm{~m}$ apart in the ophiolitic formation of the Batin (BA1) site in the wadi Tayin massif of the Sultanate of Oman. Cross-borehole open pumping experiments, as well as multi-level pumping and monitoring hydraulic tests, are performed in conductive zones that were identified from temperature and flowmeter data, but also in low-permeability zones requiring
\end{abstract}

\footnotetext{
*Corresponding author. Email address: delphine.roubinet@umontpellier.fr
} 
to manage very low pumping flow rates. The collected data are interpreted with a model implementing non-integral flow dimension, leakage and timedependent pumping flow rates. The considered modeling concepts and the estimated hydrogeological properties show that the multi-directional structural heterogeneities of ophiolitic aquifers are key features that must be considered in future hydrogeological models because they drive the hydraulic responses of these systems.

Keywords: Ophiolitic aquifer, Cross-borehole hydraulic test, Multi-level packer pumping experiment, Heterogeneous hydrosystems, Hydraulic property estimation, Variable flow-rate model

\section{1. Introduction}

2 Ophiolitic rocks are fragments of oceanic crust and upper mantle which 3 are widespread on the surface of continents along tectonic suture zones (e.g.,

4 Abbate et al., 1985; Boronina et al., 2005; Maury and Balaji, 2014; Segadelli 5 et al., 2017b; Vacquand et al., 2018, Jeanpert et al., 2019). These rocks ex6 tend from the Alps to the Himalayas through, for instance, Cyprus, Syria 7 and Oman, and are also present in various countries such as Cuba, USA, 8 Papua-New Guinea, New Caledonia and Newfoundland (Abbate et al., 1985). 9 Ophiolites are important groundwater resources in some areas (e.g., within the northern Apennines (Segadelli et al., 2017b) and in Cyprus (Boronina et al., 2005)). In Oman, ophiolite water was a key resource for the population that started in 3000 BC. Nowadays, the main fresh water supply in the towns bordering the Oman gulf including Muscat comes from sea water desalinisation, but ophiolites still provide the only source of water for 
agriculture (including dates growing, which is often the main income for villagers) in several inland areas where people built underground galleries called Aflaj (plural of Falaj) for irrigation since 5000 years. Villages developed close to the (often intermittent) rivers (wadis) that form from the ophiolite water sources often occurring at the peridotite - gabbro interface, the former forming the low permeability reservoir while the latter, fractured and often altered, draining the ophiolite massif water toward sources (Dewandel et al., 2004). In a general manner, ophiolites may impact strongly the chemical composition of the water (e.g., in western Serbia (Nikic et al., 2013) and Oman (Paukert-Vankeuren et al., 2019) ) because of the high reactivity of the rock-forming minerals which makes some water sources unsuitable for human use. Ophiolites are composed of rocks such as basalt, dolerite, gabbro and peridotite, implying that they are characterized by the coexistence of different lithological units, which can be fractured at many scales due to cooling and (multiple) chemical alteration mechanisms. The presence of structural discontinuities that control the permeability of these systems results in some similarities with the well-known and widely-studied fractured granitic rock aquifers. However, these similarities in terms of fracturation do not result in similar overall systems since the submarine conditions of formation of ophiolitic rocks and weathering after exumation lead to complex hydrogeological properties that are not well characterized yet (e.g., Boronina et al., 2003; Dewandel et al., 2005; Jeanpert et al., 2019). For instance, at meter to tens of meters scales, far from faults, hydraulic discontinuities in peridotites are often zones concentrating high density of fissures whereas granite systems are usually homogeneous, poorly-permeable matrix hosting 
pluri-meter scale, often sparsely distributed, discrete fractures.

The few studies conducted on ophiolitic aquifers show that the structural heterogeneities of these systems, resulting from the presence of both different lithological units and multi-scale hydraulic discontinuities (from fissure zones to kilometer-scale faults), control their inherent behavior under ambient conditions and their responses to forced conditions. As a result, the hydrogeological models that are built to understand and reproduce the hydrodynamic of these aquifers are based on the coexistence of various recharge and transmissivity zones, which hydraulic properties depend on the lithological units and discontinuities that are associated with the zones (e.g., Boronina et al., 2003; Dewandel et al., 2005; Segadelli et al., 2017a). These properties are estimated from different characterization techniques, including hydrograph analysis, mercury porosity and hydraulic conductivity laboratory measurements, as well as pumping tests (e.g., Boronina et al., 2003; Dewandel et al., 2005; Jeanpert et al., 2019).

The large variety of existing techniques and possible configurations that are associated with pumping experiments makes it a very useful tool for characterizing the subsurface hydraulic properties. Conducting these experiments in open boreholes, or using single or dual packers that are moved along the boreholes, provide vertically-integrated or vertically-distributed hydraulic properties, respectively. The resulting changes in pressure are monitored in either the pumped well (i.e., single-borehole experiments) or observation wells (i.e., cross-borehole experiments), which impacts the spatial extent and meaning of the estimated properties (e.g., Bear, 1979, Le Borgne et al., 2007; Day-Lewis et al., 2011). That being said, the quality of these 
estimates depends on the models that are used to interpret the collected hydraulic data. The line-source analytical solutions (e.g., Theis solution), which are widely used because they are easy to implement, are well suited for interpreting the intermediate and late-time responses that are collected while applying steady pumping flow rates. However, the assumption of a negligible effect of the pumped borehole storage might be critical when interpreting early-time data related to transient pumping flow rates. Using more sophisticated solutions, which take into account the wellbore storage effect, the flow dimension related to the structural heterogeneities, and the occurrence of leakage effects, leads to better estimates of the hydraulic properties of the studied systems, in particular when focusing on heterogeneous systems and time-dependent pumping flow rates (e.g., Lods and Gouze, 2004 , Cihan et al., 2011; Yeh and Chang, 2013).

In the context of ophiolitic aquifers, only a few studies considered pumping tests for characterizing these hydrosystems (e.g., Boronina et al., 2003; Dewandel et al., 2005; Jeanpert et al., 2019). For the Kouris catchment in Cyprus and the Koniambo massif in New Caledonia, hydraulic conductivity estimates were obtained from single-borehole pumping experiments and packer tests, respectively, that are interpreted with simple analytical solutions (Boronina et al., 2003; Jeanpert et al., 2019). For the ophiolite hardrock aquifers in Oman, the interpretation of open cross-borehole pumping experiments with a dual-porosity (or dual-permeability) model led to estimate the hydraulic conductivity and storage coefficients at various locations (Dewandel et al., 2005). These studies emphasized that the efforts for characterizing ophiolitic aquifers with pumping experiments need to be pushed 
further by focusing on (i) conducting multi-level pumping experiments (i.e., packer tests) in order to obtain vertically-distributed estimates of the hydraulic properties, (ii) using sophisticated models for improving the quality of the estimated properties, (iii) combining the complementary information provided by open borehole experiments and packer tests where the packers can be used for multi-level pumping and multi-level pressure monitoring, and (iv) developing pumping techniques and specific equipment that are adapted to low permeability zones with localized highly-permeable structures.

In this work, we address these challenges by conducting and analyzing several kinds of pumping experiments in the ophiolitic Batin East site in the Wadi Tayin massif of the Sultanate of Oman. To this end, we start by analyzing open borehole pumping experiments that were conducted in two boreholes (positioned $15 \mathrm{~m}$ apart), and we show that the considered systems cannot be characterized with vertically-integrated hydraulic properties. In order to infer vertically-distributed properties, we then consider multi-level pumping experiments, as well as multi-level cross-borehole pressure monitoring, with intervals defined from temperature and flowmeter data. In light of direct geological observations and indirect data analysis, we consider nonintegral flow dimension models with vertical leakage that are used in the context of time-dependent pumping flow rates. The corresponding results show the complexity of the studied system for which both the lithological units and discontinuities impact the estimated hydraulic properties in different proportions depending on the considered layer. In this work, we also address the issue of pumping tests in poorly-permeable zones by presenting material, experimental methods and interpretation procedures especially 
adapted to this challenge.

The site and methods are described in Section 2, the pumping experiments and their interpretation are discussed in Section 3, and the results and general conclusions are presented in Sections 4 and 5 .

\section{Site and methods}

\subsection{Site description}

The International Continental Scientific Drilling Program (ICDP) Oman Drilling Project (OmanDP) established a multi-borehole observatory in Wadi Lawayni in the Wadi Tayin massif of the Samail ophiolite in 2018 to study ongoing weathering processes, the associated hydrogeological system, and the subsurface microbiome. Wadi Tayin massif is one of the largest and most intact massifs within the Samail ophiolite. The observatory lies within the mantle peridotite section, approximately $3 \mathrm{~km}$ north of the crust-mantle transition zone (MTZ) in the south-eastern part of the massif (Figure 1). The MTZ and surrounding crustal gabbroic and mantle rocks are displaced by several kilometres along a set of NNW trending, strike-slip faults (e.g., Nicolas et al., 2000). A prominent NNW trending fault system, with unknown sense of displacement, cuts across Wadi Lawayni and the multi-borehole observatory (Figure 1). The observatory consists of a multi-borehole array of drill sites, including BA1, BA2A, BA3A and BA4A. Site BA1, which is the target site for this study, includes one fully cored, 400 meter deep hole (BA1B) and three rotary-drilled, 400 meter deep, 6-inch diameter holes (BA1A, BA1C and BA1D) (Figure 2). Borehole BA1C collapsed at 60 meters depth shortly after drilling and was abandoned. Based on core and drill cutting analysis, 
the dominate lithologies in BA1A, BA1B, BA1C and BA1D are fully serpentinized dunite in the upper 100 to 250 meters and partially serpentinized harzburgite in the deeper part of the boreholes. Preliminary analysis of borehole wall images and the core from BA1B indicate high density of fractures and veins, the majority of them sealed by carbonate or serpentine minerals. Prior sampling and analysis of groundwater in a nearby government monitoring borehole (NSHQ-14), which is situated in the same catchment as the observatory, reveal the occurrence of hyperalkaline ( $\mathrm{pH} 11-12), \mathrm{Ca}(\mathrm{OH})_{2}$-rich ¿waters, which are the product of extensive water-rock interaction (e.g., Paukert et al., 2012; Miller et al., 2016, Rempfert et al., 2017; Paukert-Vankeuren et al. 2019).

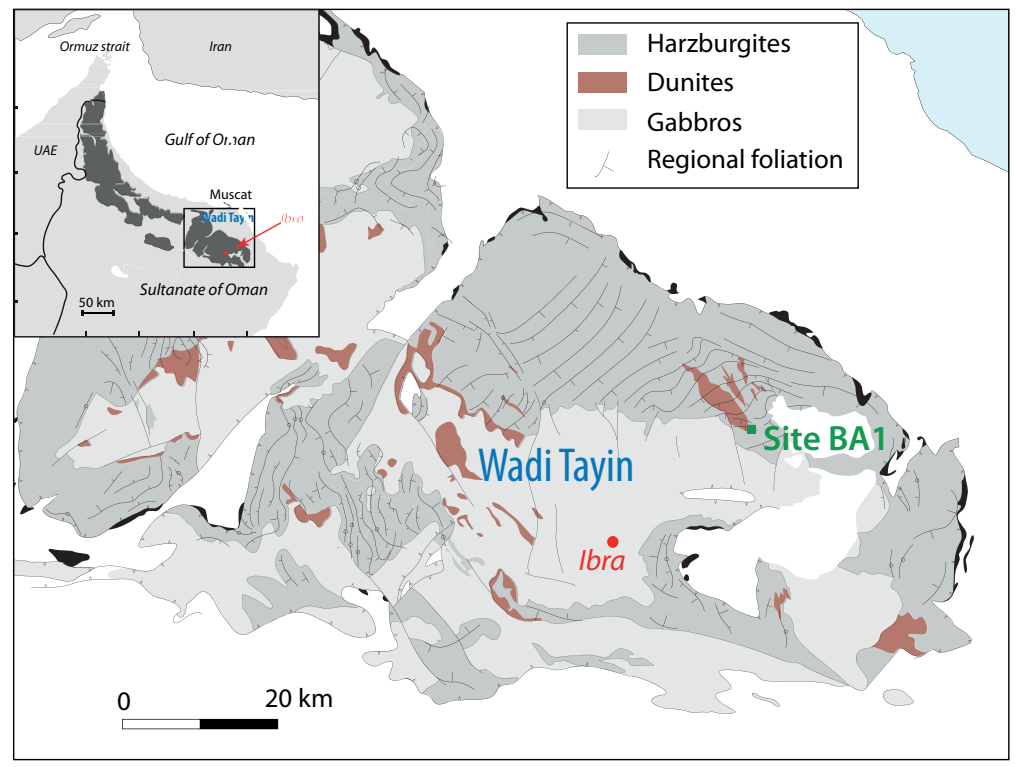

Figure 1: Map of the Wadi Tayin massif with the location of Site BA1 (modified after Noël et al. (2018), redrawn after Nicolas et al. (2000)). In inset, location of the Wadi Tayin massif in the Semail Ophiolite (North of Sultanate of Oman; redrawn after Einaudi et al. $(2000))$. 


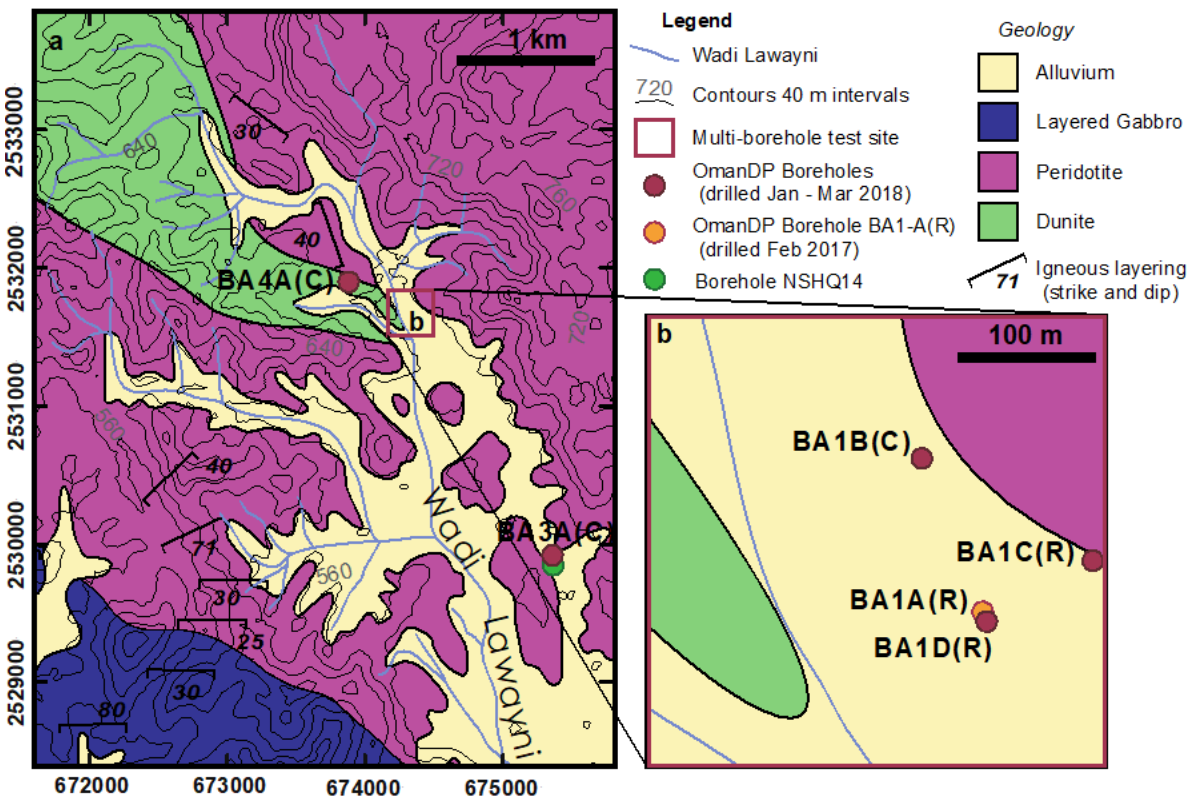

Figure 2: (a) Local geological map of Wadi Lawayni, Samail ophiolite (redrawn after Bailey (1981)). (b) Location of boreholes forming the BA1 multi-borehole observatory site.

\subsection{Material and method}

Figure 3 displays the schematic representation of the downhole part of the pumping system. It is installed from the surface using a tripod equipped with an electric chain hoist as a succession of individual parts of maximum $3 \mathrm{~m}$ length that are assembled at the surface. From the bottom to the top, the dual-packer system includes:

- the lower pressure port $\left(P_{1}\right)$ that measures the pressure below the lower packer;

- the lower packer. The two packers are $1 \mathrm{~m}$ long and can be inflated individually so that one can perform single-packer or dual-packer pumping 
test depending on the objectives;

- the pumping interval that can be set to a length ranging from 1 to $30 \mathrm{~m}$;

- the intermediary pressure port $\left(P_{2}\right)$ that measures the pressure in the measurement interval;

- the upper packer;

- the upper pressure port $\left(P_{3}\right)$ that measures the pressure above the upper packer. $P_{3} / \rho g$ measures the water column length above the upper packer, $\rho$ and $g$ being the fluid density and gravitational acceleration, respectively;

- the shut-in valve. When the packers are inflated, the valve is closed due to the weight of all the equipment (pump and pipes) above it. It is opened by pulling the pipe assemblage from the surface with the crane;

- a stack of PVC pipe of length determined in order to position the pump according to the depth of the upper packer and of the water table while keeping a distance of 10 to $150 \mathrm{~m}$ below the water test static level (WTSL);

- the pump (Grundfos SQE 1-140)

The downhole system displayed in Figure 3 is installed below the required length of screwed PVC pipes of internal diameter $48 \mathrm{~mm}$. The system is linked to the surface by the electrical wire required for powering the downhole pump as well as the data wire used to transmit the multiplexed data from the pressure sensors (that also measure temperature) and the gas hoses for inflating/deflating the packers that are included into a single cable. The data including the pressure at the three measurement levels $P_{1}, P_{2}$ and $P_{3}$ are recorded at the surface together with the two packer pressures and the water flow rate measured by a flowmeter installed in-line at the well-head. 


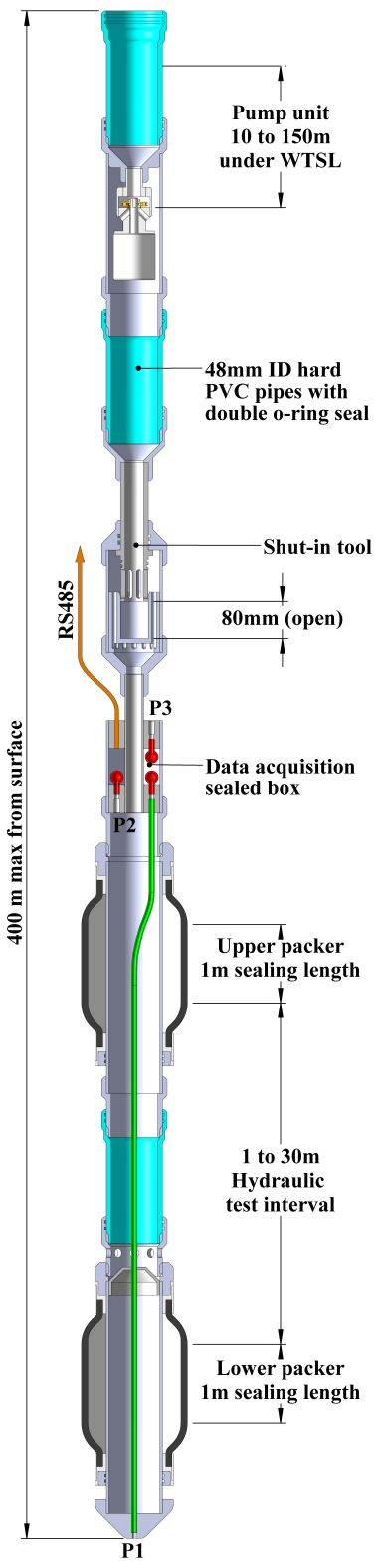

Figure 3: Schematic representation of the dual-packer system used for pumping tests. 


\subsection{Experiments and models}

Three kinds of pumping experiments are considered for characterizing the BA1 site presented in Section 2.1 with the material and method described in Section 2.2. (i) Cross-borehole pumping tests are conducted with the pressure being monitored in both (open) observation and pumped boreholes (Section 3.1). These experiments are denoted Exp1A and Exp1D when pumping in boreholes BA1A and BA1D, respectively. (ii) Multi-level pumping tests are conducted by using packers in order to isolate and pump in specific intervals of the pumped borehole while the pressure is monitored between the packers $\left(P_{2}\right)$, above the upper packer $\left(P_{3}\right)$, and below the lower packer $\left(P_{1}\right)$, as well as in the (open) observation borehole. The intervals considered for these experiments were determined from the analysis of profiles of temperature and flowmeter data, the latter profile being collected under ambient and forced hydraulic conditions. This data are presented in Appendix A with the pressures $P_{1}$ and $P_{3}$ that are monitored below and above the packers, whereas pressure $P_{2}$ is analyzed in Section 3.2. The corresponding experiments are denoted Exp2A_i1A and Exp2A_i2A when pumping is performed in the intervals $i 1 A(41-65 \mathrm{~m})$ and $i 2 A(108-132 \mathrm{~m})$ of borehole BA1A, and Exp2D_i1D and Exp2D_i2D when pumping is performed in the intervals $i 1 D$ (45-75 m) and $i 2 D(102-132 \mathrm{~m})$ of borehole BA1D. For both boreholes, we also consider the zone below $132 \mathrm{~m}$ (i.e., 133-400 m), denoted $i 3 A$ and $i 3 D$, in order to characterize the low-conductivity zone that is located at the bottom of the wells. The corresponding experiments are denoted Exp2A_i3A and Exp2D_i3D when pumping in borehole BA1A and BA1D, respectively. (iii) Finally, a cross-borehole multi-level-monitoring pumping experiment, 
denoted Exp3D (Section 3.3), was conducted by using the packer system in borehole BA1A while pumping in borehole BA1D with a Grundfos SQ2-85 pump. This test consisted in monitoring the pressure at several isolated positions in the observation borehole while the pressure is also monitored in the (open) pumped borehole.

Table 1 summarizes the pumping and observation parameters of the experiments by indicating in which borehole and at which position the pumping and monitoring are done. 'Full' corresponds to open boreholes, whereas the numbers indicate the distances in meter from the surface to the top and bottom positions of the packers that are used to consider isolated intervals. During all these experiments, the pressure was also monitored in borehole BA1B (120 m NNW of BA1A and BA1D), in which no response was recorded. This is likely due to the low permeability of the corresponding zone as shown by the log data and core analysis of this borehole (not shown).

From a modeling point of view, the fractured nature of ophiolitic aquifers leads to consider both dual-permeability and non-integral flow dimension models, the former modeling concept being used in some previous studies (Dewandel et al., 2005). Here, we focus on the latter conceptual models because of the following reasons: (i) Direct surface observations at the scale of the test site showed numerous heterogeneously distributed centimeter to decimeter-scale fractures but no large-scale hydraulic discontinuities such as fractures that would have suggested the presence of two interconnected systems of distinctly different hydraulic properties, and as such should have justified the use of dual-permeability models. (ii) The responses recorded above and below the isolated intervals during packer tests with the pressures 


\begin{tabular}{|c|c|c|c|c|}
\hline & \multicolumn{2}{|c|}{ Pumping well } & \multicolumn{2}{|c|}{ Observ. well } \\
\hline & BA1A & BA1D & BA1A & BA1D \\
\hline $\operatorname{Exp} 1 A$ & Full & - & - & Full \\
\hline $\operatorname{Exp} 1 D$ & - & Full & Full & - \\
\hline $\operatorname{Exp} 2 A \_i 1 A$ & $41-65$ & - & - & Full \\
\hline Exp2A_i2A & $108-132$ & - & - & Full \\
\hline Exp2A_i3A & $133-400$ & - & - & Full \\
\hline Exp2D_i1D & - & $45-75$ & Full & - \\
\hline Exp2D_i2D & - & $102-132$ & Full & - \\
\hline Exp2D_i3D & - & $133-400$ & Full & - \\
\hline Exp3D & - & Full & $\begin{array}{c}22-107 \\
108-132 \\
133-400\end{array}$ & $\begin{array}{l}- \\
- \\
-\end{array}$ \\
\hline
\end{tabular}

Table 1: Setup at the pumping and observation boreholes for the set of hydraulic tests

$P_{1}$ and $P_{3}$ that are reported in Appendix A, show the presence of vertical connections that can be modeled as vertical leakages in non-integral flow dimension models (Hamm and Bidaux, 1994). (iii) The results obtained in Section 3 with non-integral flow dimension models are well in agreement with the data and produce realistic estimations of the parameters and properties, thus confirming that the use of more complex models (such as dual-permeability models) is not necessary for the considered data. Dual-permeability models involve more parameters and as such more degrees of liberty that generally require making assumptions or using external data such as geophysical or geological data. In the absence of such data that would have dictated using 
dual-permeability models, the most parameter-parsimonious model must be considered as the most probable model providing a fit to the data.

In order to interpret the data collected during these experiments, we implemented a solution for transient radial flow in leaky aquifers with timedependent pumping flow rates using a fractal formalism. This representation is adapted to model hierarchical multi-scale fractured aquifers where the characteristic length of the heterogeneity is smaller than the volume investigated by the pumping test (Lods and Gouze, 2008). We consider the solution that is presented in Appendix B, which corresponds to an existing solution for transient radial flow in a fractal fractured aquifer with leakance that is extended to time-dependent pumping flow rates and non-linear skin effects. From this solution, we derived four specific models corresponding to (i) cylindrical flow without leakage (Model1), (ii) generalized radial flow without leakage (Model2), (iii) cylindrical flow with leakage (Model3), and (iv) generalized radial flow with leakage (Model/4). The parameters that distinguish these models from each other are summarized in Table 2. The derivation of the models, the associated assumptions, and their use for interpreting the data are given in Appendix C. The modeling strategy consists in determining the model that best reproduces the values collected in both the pumping and observation boreholes. When a common model cannot be found, different models and parameters are considered for each borehole. We select the best-fitting model by considering the quality of the overlap between the curves of the simulated and collected data, as well as the physical meaning of the estimated properties. For each experiment, the estimated parameters of the models are presented in tables in which the parameters corresponding 
to the selected best-fitting model are written in bold characters.

Finally, in order to have an independent estimate of the standard transmissivity $T$ (Model1), the transmissivity value estimated by interpreting the end of the recovery with Theis' method (Kruseman and de Ridder, 1990) is also provided. Since our models are based on unit-thickness aquifer representations for Model1 (as explained in Appendix C), the estimated hydraulic conductivity values of Model1 are equivalent to transmissivity values and will be directly compared to the transmissivity estimated with Theis' method. The quality of the best-fitting models is also tested by estimating the drawdown in borehole BA1B, for which, as mentioned before, no response is observed during the pumping tests. The simulated values range from 0 to $36.07 \mathrm{~cm}$, showing in the latter case the impact of heterogeneities in hydraulic properties between the boreholes.

\begin{tabular}{c|c|c} 
& Flow dimension & Leakage parameter \\
\hline Model1 & $N=2$ & $\beta=0$ \\
Model2 & $1 \leq N \leq 3, N \neq 2$ & $\beta=0$ \\
Model3 & $N=2$ & $\beta>0$ \\
Model4 & $1 \leq N \leq 3, N \neq 2$ & $\beta>0$
\end{tabular}

Table 2: Range of variations of the flow dimension $(N)$ and leakage parameter $(\beta)$ for the four models considered for data interpretation. $\beta=1 / B^{2}$ with $B$ the leakage factor in Appendix B. 


\section{Experimental data and interpretation}

\subsection{Cross-borehole pumping tests}

\subsubsection{Pumping test in borehole BA1A}

Figure 4 displays the data collected during the pumping experiment Exp $1 A$ in the pumped and observation boreholes (black curve in Figures 4 and $\mathrm{b}$, respectively). In these figures, $h$ is the difference in hydraulic head, expressed in meter of water, between the beginning of the experiment $(t=0)$ and time $t$. For technical reasons, $h$ was not monitored in the pumped well during the recovery period (Figure 4a). Figure 4c shows the pumping flow rate monitored during the experiment (black curve), which was applied for 551 minutes with an average value of $44.9 \mathrm{~L} / \mathrm{min}$, and the flow rate modeled with an exponential model (red dashed curve). The exponential model is required for interpreting some of the experiments for which the flow rate decreases noticeably. For this pumping test, the flow rate could have been considered rightly as constant, but we applied the exponential model for matter of consistency. For this pumping test no common model reproducing the data collected in both the pumped and observation boreholes could be found. The models and parameters evaluated for each of the boreholes are given in Table 3. Note that in this table, and in the rest of the manuscript, the values of the skin factor $\left(\sigma_{w}\right)$ and aquifer specific storage $\left(S_{s}\right)$ that are estimated from the pumped-borehole data are not shown because of their poor reliability (Kruseman and de Ridder, 1990). However the variations of the skin factor estimated from the pumped-borehole data are presented graphically because their irregular variations reveal clogging/unclogging phenomena.

Concerning the data collected in the pumped borehole, Model1 and Model2 
provide an acceptable fit, which could not be improved with the leakage properties that are considered in Model3 and Model4 (Figure 4a). For Model1, it is important to emphasize that additional simulations (not shown) demonstrate that $\sigma_{w}$ remains negative for $S_{s}<1 \mathrm{~m}^{-1}$, which indicates the presence of open fractures that intersect the well (Ahmed and Meehan, 2011). The presence of channelized flow in a fracture network is also indicated by the flow dimension smaller than 2 for Model2 (Le Borgne et al., 2004; Audouin et al., 2008; Verbovšek, 2009). From the results presented in Figure 4a and Table 3, this model is considered as the best-fitting model for the data collected in the pumped borehole because it is the simplest model providing the best fit to the data with the most realistic estimated parameters.

Different results are observed for the data collected in the observation borehole. The transmissivity value estimated with Model1 is consistent with that of the standard Theis' method, which is equal to $1.27 \times 10^{-4} \mathrm{~m}^{2} / \mathrm{s}$. This being said, Model2, Model3 and Model4 equally improve the fit between the simulated and collected data in comparison with Model1 (Figure 4b). In this case, Model2 is considered as the best fitting model because it is the simplest model (in comparison with Model/4) with the most realistic estimated value of $\sigma_{w}$ (in comparison with the large value of $\sigma_{w}$ estimated with Model3 and shown in Table 3).

Finally, we wish to emphasize that defining a model for each borehole presents the advantage of providing heterogeneous hydraulic properties between the pumped and observation boreholes. However, this implies that some estimated parameters are weakly reliable and must be interpreted with caution. This is the case for the skin factor $\sigma_{w}$ that is estimated from the 
332 333

adjustment done on the data collected in the observation borehole but is formally related to mechanisms occurring in the pumped borehole.
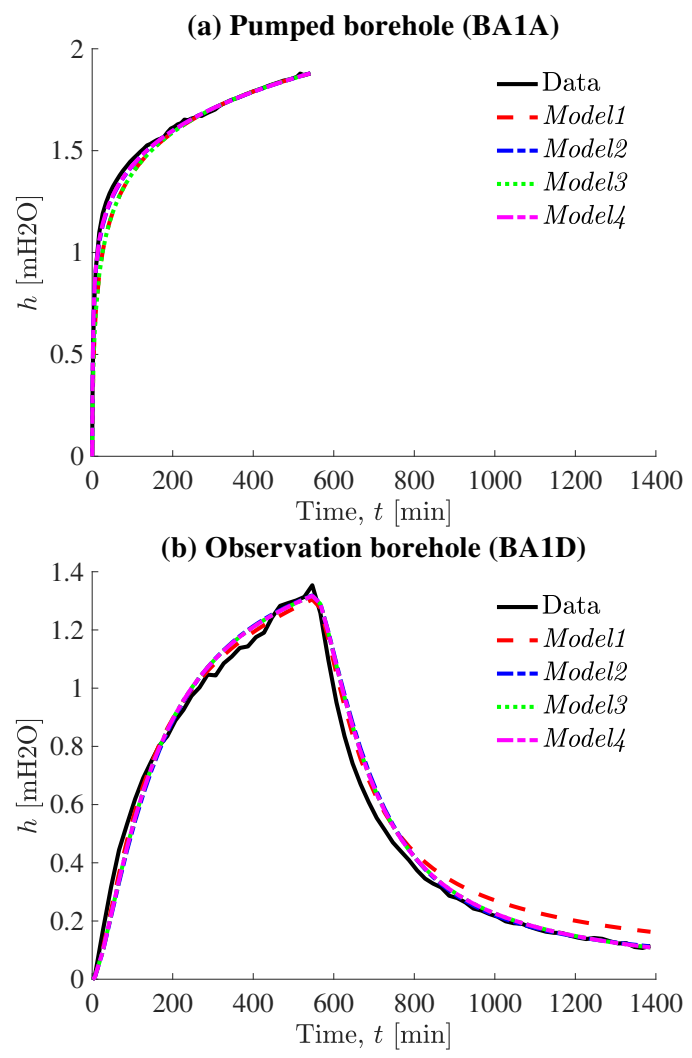

(c) Pumping flow rate

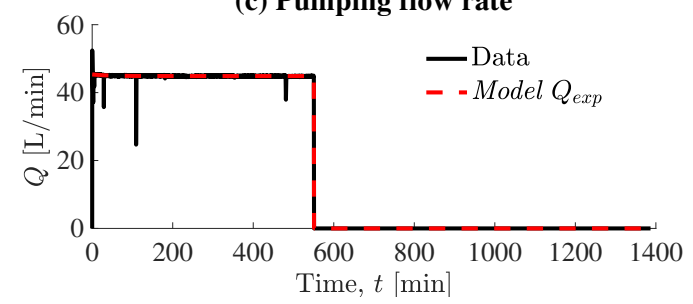

Figure 4: Data and models related to experiment Exp1A. The results obtained with the following models overlap: (a) Model1-Model3 and Model2-Model4, (b) Model2-Model3Model4. 


\begin{tabular}{|c|c|c|c|c|c|}
\hline & & Model1 & Model2 & Model3 & Model4 \\
\hline $\bar{\nabla}$ & $N$ & 2 & 1.67 & 2 & 1.64 \\
\hline$\dot{\ddot{q}}$ & $K$ & $2.05 \times 10^{-4}$ & $1.47 \times 10^{-3}$ & $2.04 \times 10^{-4}$ & $1.71 \times 10^{-3}$ \\
\hline$\tilde{z}$ & $B$ & - & - & 373.69 & 213.34 \\
\hline & $N$ & 2 & 2.27 & 2 & 2.27 \\
\hline & $K$ & $1.97 \times 10^{-4}$ & $3.48 \times 10^{-5}$ & $1.89 \times 10^{-4}$ & $3.53 \times 10^{-5}$ \\
\hline $\bar{B}$ & $S_{s}$ & $7.59 \times 10^{-4}$ & $1.35 \times 10^{-4}$ & $6.55 \times 10^{-4}$ & $1.37 \times 10^{-4}$ \\
\hline 0 & $B$ & - & - & 193.76 & 1695.73 \\
\hline & $\sigma_{w}$ & 42.56 & 10.11 & 52.10 & 10.28 \\
\hline
\end{tabular}

Table 3: Properties estimated for the models and data presented in Figure $4(\operatorname{Exp} 1 A)$.

\subsubsection{Pumping test in borehole BA1D}

In experiment Exp1D, the pumping was applied in borehole BA1D for 355 minutes and the flow rate decreased from 26.7 to $24.1 \mathrm{~L} / \mathrm{min}$ (Figure 5c). The collected data and the corresponding acceptable models are shown in Figure 5 and Table 4. As for Exp1A, a common model reproducing the data collected in both the pumped and observation boreholes could not be found. Concerning the data collected in the pumped borehole (Figure 5a), Model1 and Model3 provide an acceptable fit and the transmissivity value estimated with Model1 is consistent with that of Theis' method, which is equal to $2.15 \times 10^{-5} \mathrm{~m}^{2} / \mathrm{s}$. The best fit is obtained with Model3, whereas Model2 does not provide an acceptable fit and Modely does not improve the results obtained with Model3. These results show the importance of leakage processes for reproducing the data observed in borehole BA1D, as well as the presence of open fractures that intersect the well $\left(N=2\right.$ and $\sigma_{w}<0$ for 
$S_{s}<3 \times 10^{-2} \mathrm{~m}^{-1}$ from additional simulations).

Regarding the data collected in the observation borehole, we obtain a correct fit with all the models, whereas interpreting the end of the recovery with Theis's method is not possible because the recovery is not developed enough. Model3 is considered as the best-fitting model because the large values of skin factor in Model1 and Model2 are not realistic and Model4 does not improve the results.

\begin{tabular}{|c|c|c|c|c|c|}
\hline & & Model1 & Model2 & Model3 & Model4 \\
\hline \multirow{3}{*}{$\begin{array}{l}\bar{\nabla} \\
\vdots \\
\dot{\beta} \\
\dot{\Xi} \\
\Xi \\
0\end{array}$} & $N$ & 2 & 1.83 & 2 & 2 \\
\hline & $K$ & $2.02 \times 10^{-5}$ & $1.61 \times 10^{-4}$ & $4.5 \times 10^{-6}$ & $4.47 \times 10^{-6}$ \\
\hline & $B$ & - & - & 31.04 & 31.04 \\
\hline \multirow{5}{*}{$\begin{array}{l}\overline{0} \\
\dot{3} \\
\dot{0} \\
0 \\
0\end{array}$} & $N$ & 2 & 1.8 & 2 & 1.45 \\
\hline & $K$ & $3.21 \times 10^{-4}$ & $1.19 \times 10^{-3}$ & $3.96 \times 10^{-6}$ & $2 \times 10^{-5}$ \\
\hline & $S_{s}$ & $3.08 \times 10^{-4}$ & $1.12 \times 10^{-3}$ & $2.9 \times 10^{-5}$ & $1.43 \times 10^{-4}$ \\
\hline & $B$ & - & - & 5 & 4 \\
\hline & $\sigma_{w}$ & 206.91 & 594.53 & 1.39 & 54 \\
\hline
\end{tabular}

Table 4: Properties estimated for the models and data presented in Figure 5 (Exp1D).

\subsection{Multi-level pumping tests \\ 3.2.1. Pumping tests in borehole BA1A}

The multi-level pumping experiments conducted in borehole BA1A lead to the data and models shown in Figure 6 and Table 5 for experiment Exp2A_i1A and Figure 7 and Table 6 for experiment Exp2A_i2A. No results are presented for experiment Exp2A_i3A because it was not possible to pump in the considered interval (133-400 m). In this case, we estimate 

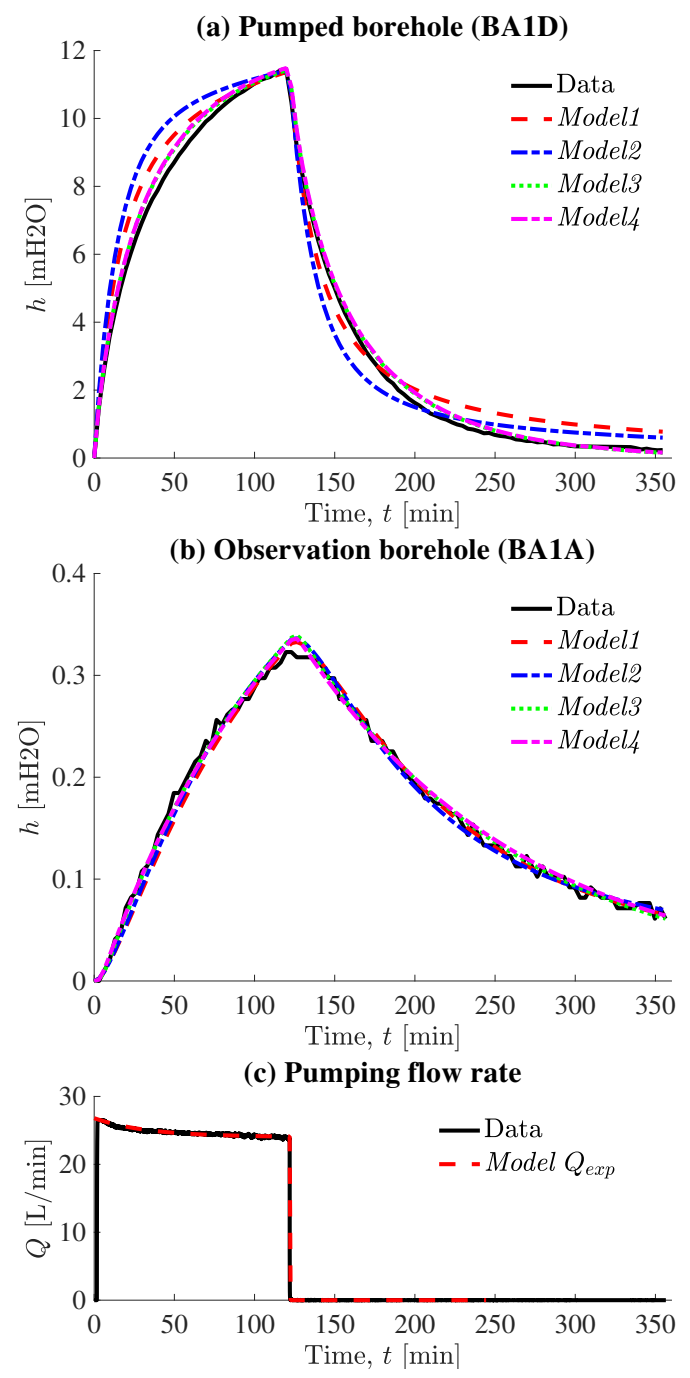

Figure 5: Data and models related to experiment Exp1D. The results obtained with Model3 and Model4 overlap.

that the transmissivity of this zone is smaller than $7 \times 10^{-8} \mathrm{~m}^{2} / \mathrm{s}$, which is the smallest transmissivity in which we could pump with that pumping equipment.

In experiment Exp2A_i1A, a multiple-step pumping flow rate is applied 
(Figure 6c). The data collected in the pumped (Figure 6a) and observation (Figure 6b) wells are interpreted by dividing the pumping flow rate data into 5 sub-steps in order to account as thinly as possible for the flow rate variations, and are modeled by considering flow-rate-dependent values of the skin factor $\sigma_{w}$ (Figure 6d). Note that the flow-rate dependence of the skin factor has been observed and studied in previous work, in particular in step-drawdown tests (Jacob, 1947; Rorabaugh, 1953; van Everdingen, 1953; Kruseman and de Ridder, 1990). Furthermore, the model parameters provided in Table 5 are characteristic of flow in fractured media with $\sigma_{w}<0$ when $N=2$ for Model1 and Model3 and $N=1$ for Model2 and Model4.

The flow dimension of Model2 and Model4 indicates the presence of a channel, or several independent channels, that dominate the flow. The high values of $\sigma_{w}$ estimated with these models show either (i) clogging of the channel that intersects the pumping well or (ii) the channel does not intersect the pumping well and hydraulic connection occurs through permeable porous media or fissures. Note that the high values of $\sigma_{w}$ can be explained by the fact that the interpretation of the skin factor with the generalized radial flow model is not explicit when $N \neq 2$ because the pumping chamber geometry of the model does not correspond to its real geometry. The difference between these two geometries impacts the value of the skin factor, which could explain why high values of the skin factor can be found for low flow dimension Hamm and Bidaux, 1996; Lods and Gouze, 2004). Model2 is selected as the most realistic model because (i) it provides a much better fit with the collected data than Model1 with an almost-linear increase of the skin factor and (ii) Model3 and Model4 do not improve the results obtained with Model2. The 
transmissivity values estimated with Theis' method are 5 times greater than those obtained for the pumped and observation boreholes with Model1, which is explained by the inadequacy of Model1.

\begin{tabular}{c|cccc} 
& Model1 & Model2 & Model3 & Model4 \\
\hline$N$ & 2 & $\mathbf{1}$ & 2 & 1 \\
$K$ & $2.37 \times 10^{-5}$ & $\mathbf{1 . 6} \times \mathbf{1 0}^{-\mathbf{2}}$ & $2.31 \times 10^{-5}$ & $1.56 \times 10^{-2}$ \\
$S_{s}$ & $1.12 \times 10^{-3}$ & $\mathbf{1 . 1} \times \mathbf{1 0}^{-\mathbf{1}}$ & $1.1 \times 10^{-3}$ & $1.09 \times 10^{-1}$ \\
$B$ & - & - & 55.57 & 172.79 \\
$\sigma_{w}$ & & \multicolumn{2}{c}{ cf Figure $6 \mathrm{~d}$}
\end{tabular}

Table 5: Properties estimated for the models and data presented in Figure6 6xp2A_i1A).

For experiment Exp2A_i2A, a common model reproducing the data collected in the pumped and observation boreholes could not be found. The results presented in Figure 7 and Table 6 show that the fit to the data that is obtained with Model1 can be improved with Model3, whereas Model2 and Model4 do not improve these results. The transmissivity values estimated with Theis's method are equal to $1.06 \times 10^{-5} \mathrm{~m}^{2} / \mathrm{s}$ and $3.94 \times 10^{-5} \mathrm{~m}^{2} / \mathrm{s}$ for the pumped and observation boreholes, respectively, corresponding to larger and smaller values, respectively, than that obtained with Model1.

\subsubsection{Pumping tests in borehole BA1D}

The data and models related to the multi-level pumping tests conducted in borehole BA1D are shown in Figure 8 and Table 7 for experiment Exp2D_i1D, Figure 9 and Table 8 for experiment Exp2D_i2D, and Figure 10 and Table 9 for experiment Exp2D_i3D. For experiments Exp2D_i1D and Exp2D_i2D, a common model could not be found to reproduce the data collected in both 

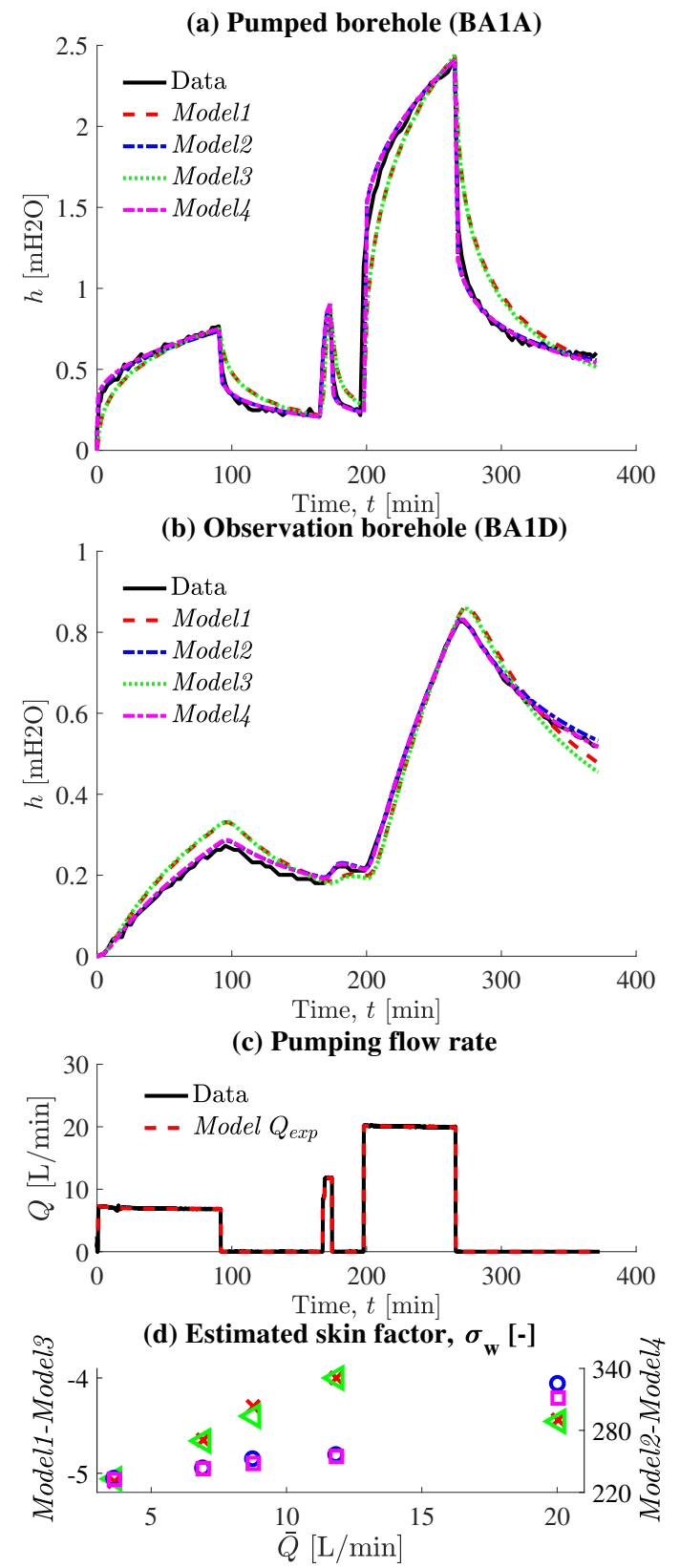

Figure 6: Data, models, and parameters related to experiment Exp2A_i1A. (a-b) The results obtained with the following models overlap: Model1-Model3 and Model2-Model4. In (d) the changes in the estimated skin factor $\sigma_{w}$ with the step average flow rate $\bar{Q}$ are shown for Model1-Model3 (red crosses-green triangles, left axis) and Model2-Model4 (blue circles-magenta squares, right axis). 

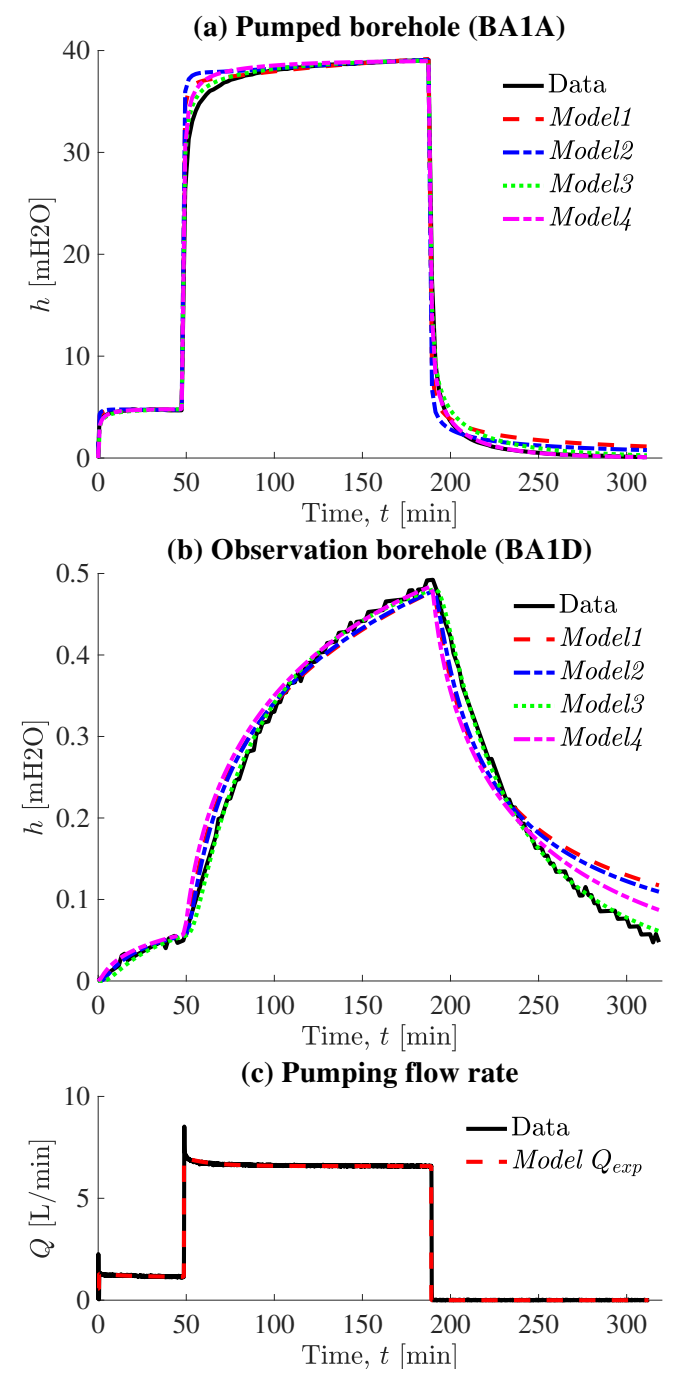

Figure 7: Data and models related to experiment Exp2A_i2A.

the pumped and observation boreholes, implying that the models are defined for each borehole. For experiment Exp2D_i3D, no response was observed in the observation borehole implying that the models are only defined for the pumped borehole.

Concerning experiment Exp2D_i1D, the results reported in Figure $8 \mathrm{a}$ and 


\begin{tabular}{|c|c|c|c|c|c|}
\hline & & Model1 & Model2 & Model3 & Model4 \\
\hline \multirow{3}{*}{$\begin{array}{l}\bar{\Xi} \\
\vdots \\
\dot{3} \\
\dot{\Xi} \\
\dot{\Xi} \\
\dot{0}\end{array}$} & $N$ & 2 & 2.1 & 2 & 2 \\
\hline & $K$ & $6.15 \times 10^{-6}$ & $4.59 \times 10^{-6}$ & $2.74 \times 10^{-6}$ & $2.65 \times 10^{-6}$ \\
\hline & $B$ & - & - & 28.53 & 22.41 \\
\hline \multirow{5}{*}{0} & $N$ & 2 & 2.2 & 2 & 1.2 \\
\hline & $K$ & $5.6 \times 10^{-5}$ & $1.54 \times 10^{-5}$ & $2.5 \times 10^{-5}$ & $10^{-2}$ \\
\hline & $S_{s}$ & $2.41 \times 10^{-4}$ & $9.74 \times 10^{-5}$ & $3.24 \times 10^{-4}$ & $8.64 \times 10^{-3}$ \\
\hline & $B$ & - & - & 24.88 & 111.24 \\
\hline & $\sigma_{w}$ & 0 & 0 & 0 & $-2.9 \times 10^{-4} ;-7 \times 10^{-5}$ \\
\hline
\end{tabular}

Table 6: Properties estimated for the models and data presented in Figure 7 (Exp2A_i2A).

Table 7 show that Model1 and Model2 do not provide an acceptable fit of the recovery data recorded in the pumped borehole, whereas Model3 and Model/4 fit well the data. The best-fitting model (Model/4) corresponds to a non-cylindrical flow that is dominated by a channel $(N=1)$ with important leakage $(B=2.92)$. Additional simulations show that $\sigma_{w}<0$ when $S_{s}<$ $2 \times 10^{-1} \mathrm{~m}^{-1}$, which indicates the presence of open fractures that intersect the well. Similar results are observed for the data collected in the observation borehole since the fit obtained with Model1 could not be improved with Model2 whereas Model3 and Model/4 fit well the data, the best fit being obtained with Model 4 (Figure 8p). In this case, $\sigma_{w}$ has no effect on the results ( $\sigma_{w}=0$ ), implying that the estimated values of $K / S_{s}$ and $S_{s}$ are reliable, the high values of $S_{s}$ being characteristic of semi-confined aquifers. Finally, the hydraulic conductivity values estimated with Model1 are consistent with the transmissivity values obtained using Theis' method, which give $5.53 \times 10^{-6}$ 
and $1.37 \times 10^{-4} \mathrm{~m}^{2} / \mathrm{s}$ for the pumped and observation well, respectively.
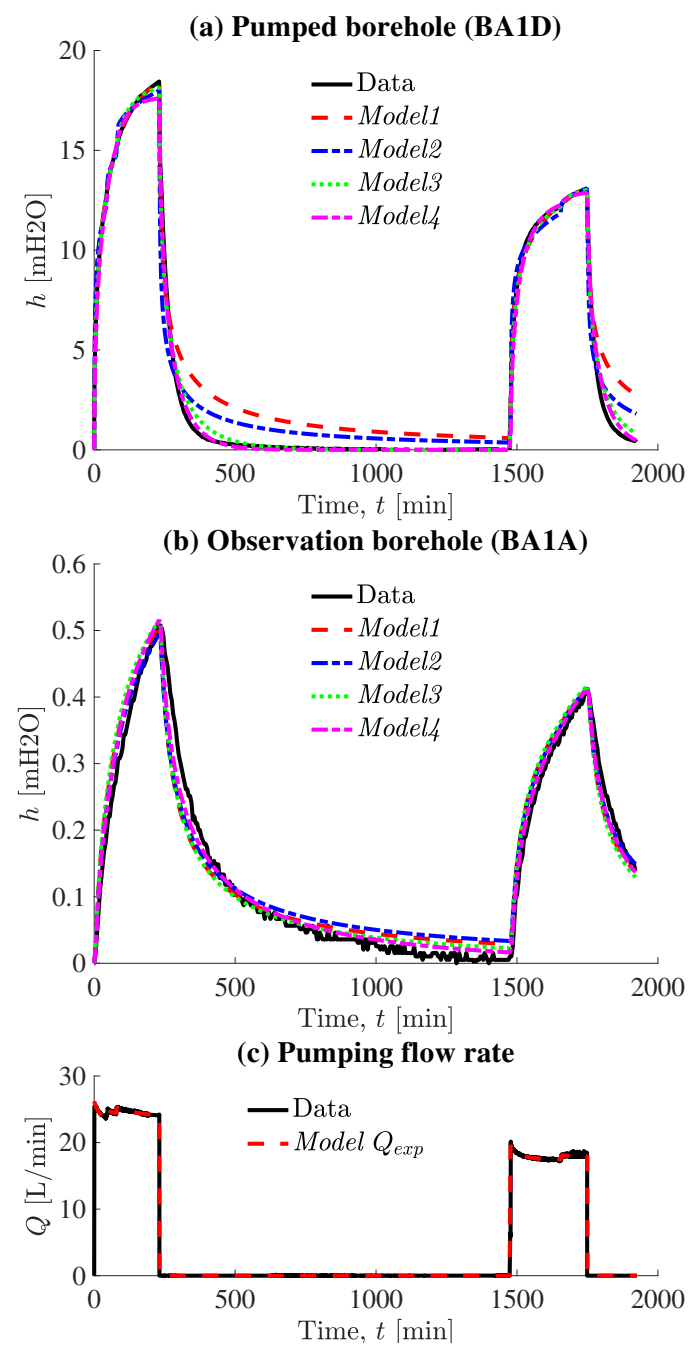

Figure 8: Data and models related to experiment Exp2D_i1D.

427

When studying the interval 102-132 m (experiment Exp2D_i2D), we consider the four-step pumping flow rate presented in Figure 9 c. Figure 9 a shows that Model1 and Model2 do not fit the recovery, whereas Model3 and Model4 provide a perfect fit to the data collected in the pumped borehole, resulting 


\begin{tabular}{|c|c|c|c|c|c|}
\hline & & Model1 & Model2 & Model3 & Model4 \\
\hline$\overline{0}$ & $N$ & 2 & 2.05 & 2 & 1 \\
\hline$\dot{q}$ & $K$ & $9.4 \times 10^{-6}$ & $1.06 \times 10^{-5}$ & $3.94 \times 10^{-6}$ & $1.3 \times 10^{-4}$ \\
\hline$\Xi$ & $B$ & - & - & 17.13 & 2.92 \\
\hline & $N$ & 2 & 1.89 & 2 & 1.67 \\
\hline & $K$ & $1.92 \times 10^{-4}$ & $3.68 \times 10^{-4}$ & $1.84 \times 10^{-4}$ & $1.26 \times 10^{-3}$ \\
\hline 3 & $S_{s}$ & $1.38 \times 10^{-3}$ & $2.49 \times 10^{-3}$ & $1.34 \times 10^{-3}$ & $7.83 \times 10^{-3}$ \\
\hline 0 & $B$ & - & - & 197.35 & 105.4 \\
\hline & $\sigma_{w}$ & 0 & 0 & 0 & 0 \\
\hline
\end{tabular}

Table 7: Properties estimated for the models and data presented in Figure 8 (Exp2D_i1D).

in considering the simplest model (i.e., Model3) as the best-fitting model. For the data collected in the observation borehole, all models provide an acceptable fit to the data, implying that the simplest model (i.e., Model1) is considered as the best-fitting model. In the case of the pumped-borehole models, the decrease in the slope of $\sigma_{w}$ versus $\bar{Q}$ when $\bar{Q}=1.79 \mathrm{~L} / \mathrm{min}($ Figure 9d) is characteristic of unclogging phenomena, while the good fit between the collected and simulated data suggests that these phenomena are localized in the borehole skin. Additional analyses point out that $\sigma_{w}$ is negative only when $S_{s}$ is smaller than $1.9 \times 10^{-5} \mathrm{~m}^{-1}$, which indicates the absence of fractures that intersect the wells with apertures larger than in the formation.

Because of the low permeability of the interval 133-400 m (experiment Exp2D-_i3D), very small flow rates were applied when studying this zone (Figure 10b). During this experiment, no response was recorded in the ob- 

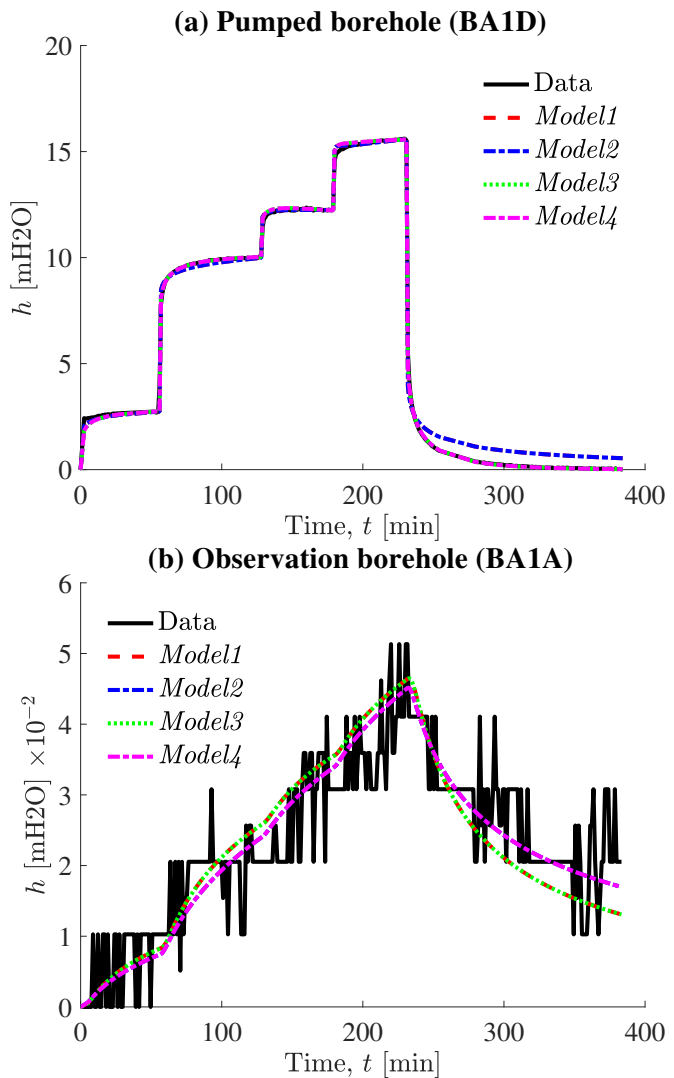

(c) Pumping flow rate
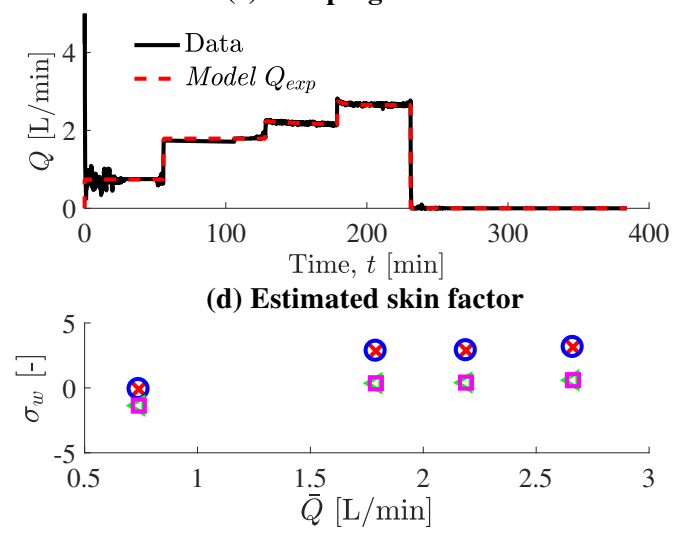

Figure 9: Data and models related to experiment Exp2D_i2D. The results obtained with the following models overlap: (a) Model1-Model2 and Model3-Model4, (b) Model1-Model3 and Model2-Model4. In (d) the changes in the estimated skin factor $\sigma_{w}$ with the step average flow rate $\bar{Q}$ are shown for Model1 (red crosses), Model2 (blue circles), Model3 (green triangles) and Model4 (magenta squares). 


\begin{tabular}{|c|c|c|c|c|c|}
\hline & & Model1 & Model2 & Model3 & Model4 \\
\hline \multirow{3}{*}{$\begin{array}{l}\bar{\Xi} \\
\dot{3} \\
\dot{0} \\
\dot{\Xi} \\
\vec{\Xi}\end{array}$} & $N$ & 2 & 2 & 2 & 2 \\
\hline & $K$ & $4.5 \times 10^{-6}$ & $4.5 \times 10^{-6}$ & $2.49 \times 10^{-6}$ & $2.49 \times 10^{-6}$ \\
\hline & $B$ & - & - & 10.03 & 10.03 \\
\hline \multirow{5}{*}{$\begin{array}{l}\overline{0} \\
\dot{3} \\
\dot{\theta} \\
\dot{0}\end{array}$} & $N$ & 2 & 1.51 & 2 & 1.51 \\
\hline & $K$ & $1.79 \times 10^{-4}$ & $3.79 \times 10^{-3}$ & $1.79 \times 10^{-4}$ & $3.79 \times 10^{-3}$ \\
\hline & $S_{s}$ & $1.54 \times 10^{-3}$ & $1.89 \times 10^{-2}$ & $1.54 \times 10^{-3}$ & $1.89 \times 10^{-2}$ \\
\hline & $B$ & - & - & - & - \\
\hline & $\sigma_{w}$ & 0 & 0 & 0 & 0 \\
\hline
\end{tabular}

Table 8: Properties estimated for the models and data presented in Figure 9 (Exp2D_i2D).

servation borehole BA1A and the small flow rates were difficult to apply and maintain, resulting in irregular initial flow rates. In this case, the response recorded in the pumped borehole is interpreted by dividing the pumping flow rate data into 9 sub-steps. The results shown in Figure 10 and Table 9 are obtained by using, as before, a step-wise exponential model to reproduce the pumping flow rate in Model1, Model2, Model3 and Model4 (dashed red curve in Figure 10p). In order to demonstrate the importance of this exponential model, we also show the results obtained with Model3', which considers a step-wise constant pumping flow rate (dash-dot blue curve in Figure $10 \mathrm{p}$ ). These results show that Model1 does not provide an acceptable fit to the data because, namely, of an important increase in the drawdown at the beginning of the last pumped steps. Attempt to reduce these peaks leads to models with unrealistic values of the wellbore storage coefficient (not shown). On the contrary, these peaks are eliminated with Model2, Model3 and Model4, 
Model3 being the best-fitting model. The transmissivity value estimated with Model1 is consistent with that of the standard Theis' method, which is equal to $6.71 \times 10^{-8} \mathrm{~m}^{2} / \mathrm{s}$. Furthermore, Figure $10 \mathrm{c}$ shows that increasing $\bar{Q}$ from 0.079 to $0.267 \mathrm{~L} / \mathrm{min}$ with Model1, Model2, Model3 and Model4 results in decreasing $\sigma_{w}$. This behavior is characteristic of the occurrence of an unclogging phenomenon. On the contrary, when using Model3', this skin factor behavior is not observed (not shown) and a large discrepancy is observed during the recovery between the simulated and collected data (dotted balck curve in Figure 10a), demonstrating the importance of using a step-wise exponential model for representing the pumping flow rate.

\begin{tabular}{c|cccc} 
& Model1 & Model2 & Model3 & Model4 \\
\hline$N$ & 2 & 2.99 & $\mathbf{2}$ & 2.09 \\
$K$ & $6.99 \times 10^{-8}$ & $1.32 \times 10^{-8}$ & $\mathbf{2 . 3} \times \mathbf{1 0}^{-\mathbf{8}}$ & $2.11 \times 10^{-8}$ \\
$B$ & - & - & $\mathbf{0 . 2 1}$ & 0.26
\end{tabular}

Table 9: Properties estimated for the models and data presented in Figure 10 (Exp2D_i3D).

\subsection{Cross-borehole multi-level-monitoring pumping experiment}

In experiment Exp3D, a pumping flow rate of $20.17 \mathrm{~L} / \mathrm{min}$ was applied during $338 \mathrm{~min}$ in borehole BA1D while monitoring the pressure in the intervals $i 1 A^{\prime}(22-107 \mathrm{~m}), i 2 A(108-132 \mathrm{~m})$, and $i 3 A(133-400 \mathrm{~m})$ in borehole BA1A (Figure 11). Here, the data cannot be interpreted with the models presented before because the flow rate applied to each interval is not known. The data collected during this experiment are rather used to confirm and complete the information previously obtained on the connections between 

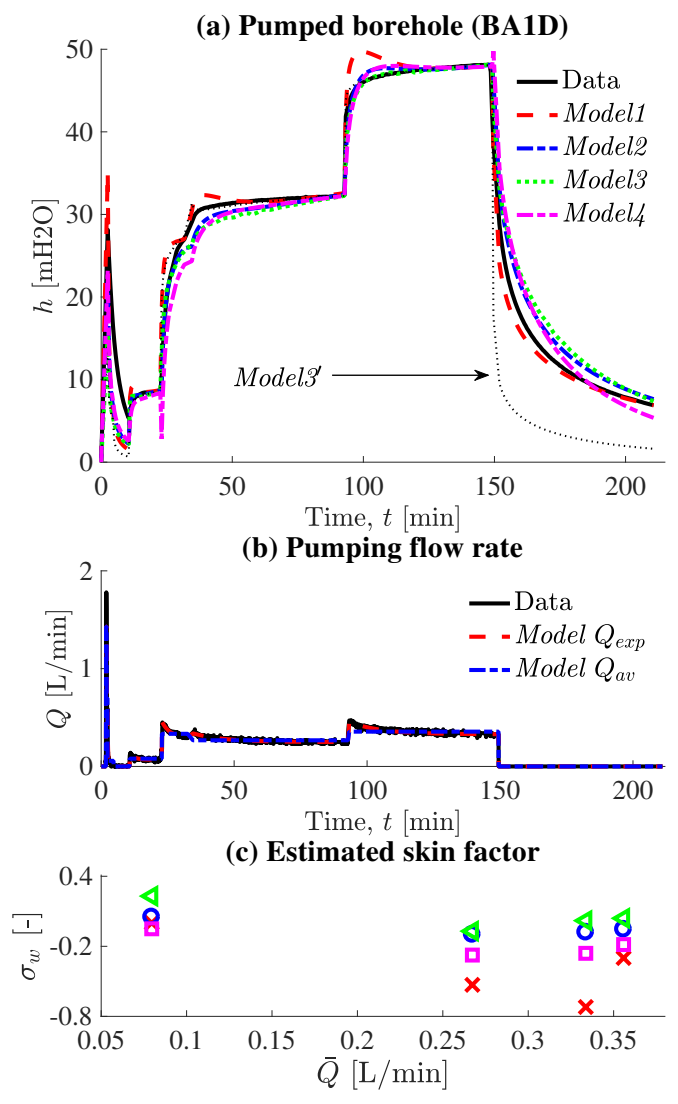

Figure 10: Data, models, and parameters for experiment Exp2D_i3D. In (c) the changes in $\sigma_{w}$ with the step average flow rate $\bar{Q}$ are shown for Model1 (red crosses), Model2 (blue circles), Model3 (green triangles) and Model4 (magenta squares).

the pumped and observation boreholes, as well as between various intervals of these boreholes.

From the data reported in Figure 11, we determine that the reaction times of intervals $i 1 A^{\prime}, i 2 A$, and $i 3 A$ are 4,1 , and $9 \mathrm{~min}$, respectively. These observations can be related to the results presented in Section 3.2.1 where the multi-level pumping tests conducted in borehole BA1A are interpreted with various models. Using Model1 leads to show that (i) the diffusivity estimated 


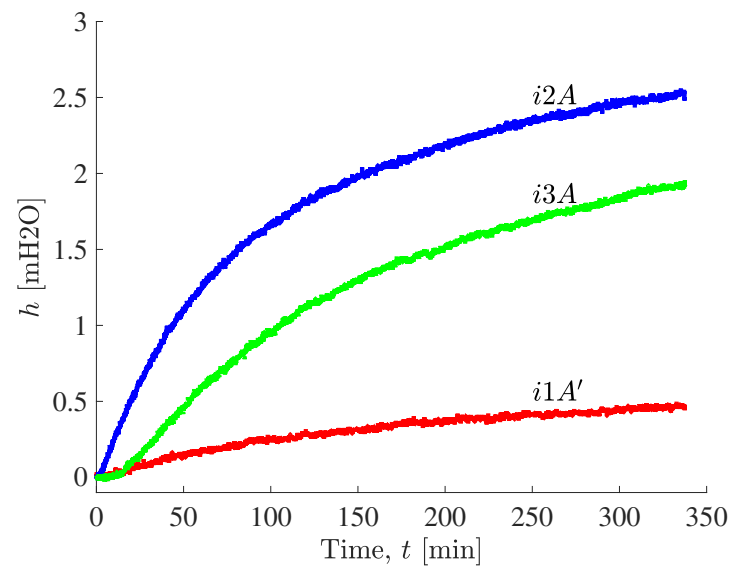

Figure 11: Data monitored in intervals $i 1 A^{\prime}, i 2 A$ and $i 3 A$ of the observation borehole BA1A while pumping in borehole BA1D (experiment Exp3D). 


\section{Discussion}

The parameters inferred from modelling the pumped well drawdown reveal the hydraulic properties in the vicinity of the pumping well. Conversely, those evaluated from the observation well data are effective parameters integrating all the hydraulic structures from surface to depth including local draining zones. Nevertheless, the parameters evaluated at the observation well, when different from those inferred at the pumping well, enlighten the heterogeneity and probable anisotropy of the studied system.

Figure 12 summarizes the main conclusions that are obtained from the (non-unique) models presented in Section 3 , including the open-borehole tests $\operatorname{Exp} 1 A$ and $\operatorname{Exp} 1 D$ and the cross-borehole multi-level hydraulic experiments Exp2A and Exp2D. Interpreting the open-borehole tests Exp1A and Exp1D with Model1 leads to a transmissivity of BA1D one order of magnitude lower than that of BA1A with leakage in the former case. These results, which are a first indication of the horizontal and vertical heterogeneities that characterize the system, are consistent with the open-borehole experiments in Dewandel et al. (2005) that could be interpreted with $N=2$. Furthermore, in the case of $\operatorname{Exp} 1 D$, the need for considering important leakage processes can be related to the presence of an overlying aquifer zone located above BA1D casing base depth, in the alluvium (Figure A.16), at which a productive interval $(26-27 \mathrm{~m})$ is detected by the flowmeter (Figure A.14 $)$.

Concerning the cross-borehole multi-level hydraulic experiments Exp2A and Exp2D, the presented results emphasize the strong variability of the hydraulic properties induced by the heterogeneities of the geological structures. For the upper part of the system (i.e., intervals $i 1 A$ and $i 1 D$ located between 
41 and $75 \mathrm{~m}$ ), results indicate the presence of highly conductive fractures $(N<2$ in Exp2A_i1A and Exp2D_i1D) with different behaviors depending on the considered pumped borehole. When pumping in borehole BA1A (Exp2A_i1A), a unique model with $N=1$ is found to interpret the data collected in both boreholes. This shows that the hydraulic responses of BA1A and BA1D are driven by a highly conductive channelized structure $(N=1)$, for example an extended, open or partially mineralized fracture within which a 1D channel is developed. The two boreholes do not necessarily intersect the channel, they can be connected to it by a conduct in which the flow rate becomes rapidly permanent. On the contrary, when pumping in BA1D (Exp2A_i1D), two different leakage models are required to describe the data collected in the boreholes with an increase in the hydraulic conductivity and flow dimension from the pumped to the observation-borehole model. In this case, the need for leakage models with high values of the leakages for the pumped-borehole model, as well as the heterogeneities in properties between the boreholes with $N>1$ for the observation-borehole model, show that the hydraulic responses are only partially determined by the highly conductive channelized structure previously described. That is, the water pumped in the upper tested interval of BA1D comes from the highly conductive channelized structure previously described that connect the upper intervals of the considered boreholes (horizontal connections), but also from underlying and overlying rocks surrounding BA1D (vertical connections). Thus additional vertical flow contributions are present when pumping in BA1D, whereas the horizontal connections are sufficient for the pumping in BA1A with similar pumping flow rates. 
Concerning the middle part of the system (i.e., intervals $i 2 A$ and $i 2 D$ located between 102 and $132 \mathrm{~m}$ ), the value of the estimated flow dimension $(N=2)$ for the pumped and observation boreholes in Exp2A_i2A and Exp2D_i2D, shows that the observed hydraulic responses are not determined by the presence of conductive structures with channelized flow as for the upper part of the system. Conversely, these models are related to leakage properties except for the observation-borehole model of Exp2D_i2D for which a high value of the hydraulic conductivity is obtained $\left(K=1.8 \times 10^{-4} \mathrm{~m} / \mathrm{s}\right)$. This indicates the presence of heterogeneities in the directions of the flows that contribute to the pumping: (i) the pumping in BA1A is supplied by both horizontal and vertical flows that are located around and far from the pumped borehole, and (ii) the pumping in BA1D is supplied by horizontal and vertical flows close to the pumped borehole, and only horizontal flows around borehole BA1A. This might be related to the location of BA1A for which highly conductive structures of the upper part of the system was detected (see above). Indeed, considering that BA1A is surrounded by these structures, one can speculate that they contribute to the water pumped in BA1D by flowing from the upper to the middle part of the system through borehole BA1A and flowing horizontally in the middle part of the system from BA1A to BA1D. This explains that there is no vertical flow around BA1A when pumping in BA1D and that there is no counterpart behavior observed when pumping in BA1A.

Finally, the pumping experiments conducted by isolating the lower part of the system (i.e., intervals $i 3 A$ and $i 3 D$ located between 133 and $400 \mathrm{~m}$ ) also show a potential impact of the localization of the wells regarding the 
conductive structures of the system. Whereas it was not possible to pump water from BA1A (Exp2A_i3A) because the transmissivity of this layer was too low, we observe a different behavior in BA1D for which the data collected in the pumped borehole are well described with a leakage model (Exp2D_i3D). In this case, the pumped water is supplied by vertical connections occurring around the pumped borehole, which are coming from the middle part of the system that is located directly above the considered area (i.e., without intermediary poorly-permeable zones) and connected to the upper highly transmissive part of the system through BA1A. The differences between Exp2A_i3A and Exp2D_i3D can be explained by heterogeneities in the vertical hydraulic properties implying that there is no flow exchanges between the middle and lower parts of the system in the former case, whereas these exchanges occur in the latter.

\section{Conclusions}

The cross-borehole multi-level hydraulic experiments presented in Section 3 show a complex behavior of the ophiolitic hard-rock aquifer located within the BA1 site of the Sultanate of Oman. The discussion provided in Section 4 explains this behavior by the presence of highly transmissive structures in the upper part of the system and different locations of the boreholes into these structures, resulting in strong geological and hydraulic heterogeneities in all directions. Within a $15 \mathrm{~m}$ area, this study reveals degrees of heterogeneities going from 1D channelized flows sparsely connected to far-field resources to 2D standard systems supplied by nearby surrounding zones. 
The characterization previously described required to conduct hydraulic tests in zones with variable permeability going from highly to poorly conductive areas. In the latter case, pumping at very small flow rates (smaller than $1 \mathrm{~L} / \mathrm{min}$ ) is a technical challenge for which decreasing flow rates cannot be avoided. Whereas this behavior has never been considered in the data interpretation of existing studies, we developed models that are able to take into account this feature, and we show that this characteristic of the pumping flow rate is critical for interpreting the experiments.

The experiment interpretation was done using four transient radial solutions relying on various assumptions going from cylindrical flow without leakage to generalized radial flow with leakage. We believe that the data analysis methodology and the parameter estimation strategy developed for this work should be useful for interpreting other pumping experiments specifically in low permeability heterogeneous systems and when vertical leakages are important. In addition, the efficiency of these semi-analytical models makes them an ideal tool for conducting parametric sensitivity analysis and inverting experimental data in the context of complex parameter sets.

The use of fractional flow models is justified in this work by direct geological observations and the need to consider vertical leakages, and confirmed by the satisfying curve-fitting and coherent parameter and property estimates. Despite the fractured nature of ophiolitic aquifers, the adequacy of the dualpermeability concept for describing these systems is an open question, in particular because there is no evidence of large-scale fractures embedded into a poorly-permeable matrix as observed for granitic systems. The doubt about a potential dual-permeability behavior of ophiolitic aquifers requires to 
623

629

integrate vertical leakages in such models and to collect additional data such as breakthrough curves from chemical tracer experiments. Future work for the site considered in this study will focus on this characterization method with the objective of improving our ability to characterize ophiolitic aquifers and understanding their behavior.

\section{Notations}

$S_{s} \quad$ Aquifer specific storage $\left[\mathrm{m}^{-1}\right]$

$K \quad$ Hydraulic conductivity $\left[\mathrm{m} \mathrm{s}^{-1}\right]$

$T=b K \quad$ Transmissivity $\left[\mathrm{m}^{2} \mathrm{~s}^{-1}\right]$

$B \quad$ Leakage factor $[\mathrm{m}]$

$\beta \quad$ Leakage parameter $\left[\mathrm{m}^{-2}\right]$

$h \quad$ Drawdown $[\mathrm{m}]$

$r \quad$ Distance from the well $[\mathrm{m}]$

$N \quad$ Flow dimension [-]

$r_{w} \quad$ Well-aquifer exchange radius $[\mathrm{m}]$

$b \quad$ Ortho-radial extent $[\mathrm{m}]$

$S_{w} \quad$ Well storage coefficient $\left[\mathrm{m}^{2}\right]$

$\sigma_{w} \quad$ Skin factor [-]

$Q \quad$ Pumping flow rate $\left[\mathrm{m}^{3} \mathrm{~s}^{-1}\right]$

$\bar{Q} \quad$ Pumping step average flow rate $\left[\mathrm{m}^{3} \mathrm{~s}^{-1}\right]$

\section{Acknowledgments}

We would like to thank Prof. Peter Kelemen, Prof. Damon Teagle and Dr. Jude Coggon for their overall support, and Eng. Zaher Al Sulaimani, Mazin Al Sulaimani from the Oman Water Centre and AZD Engineering, 


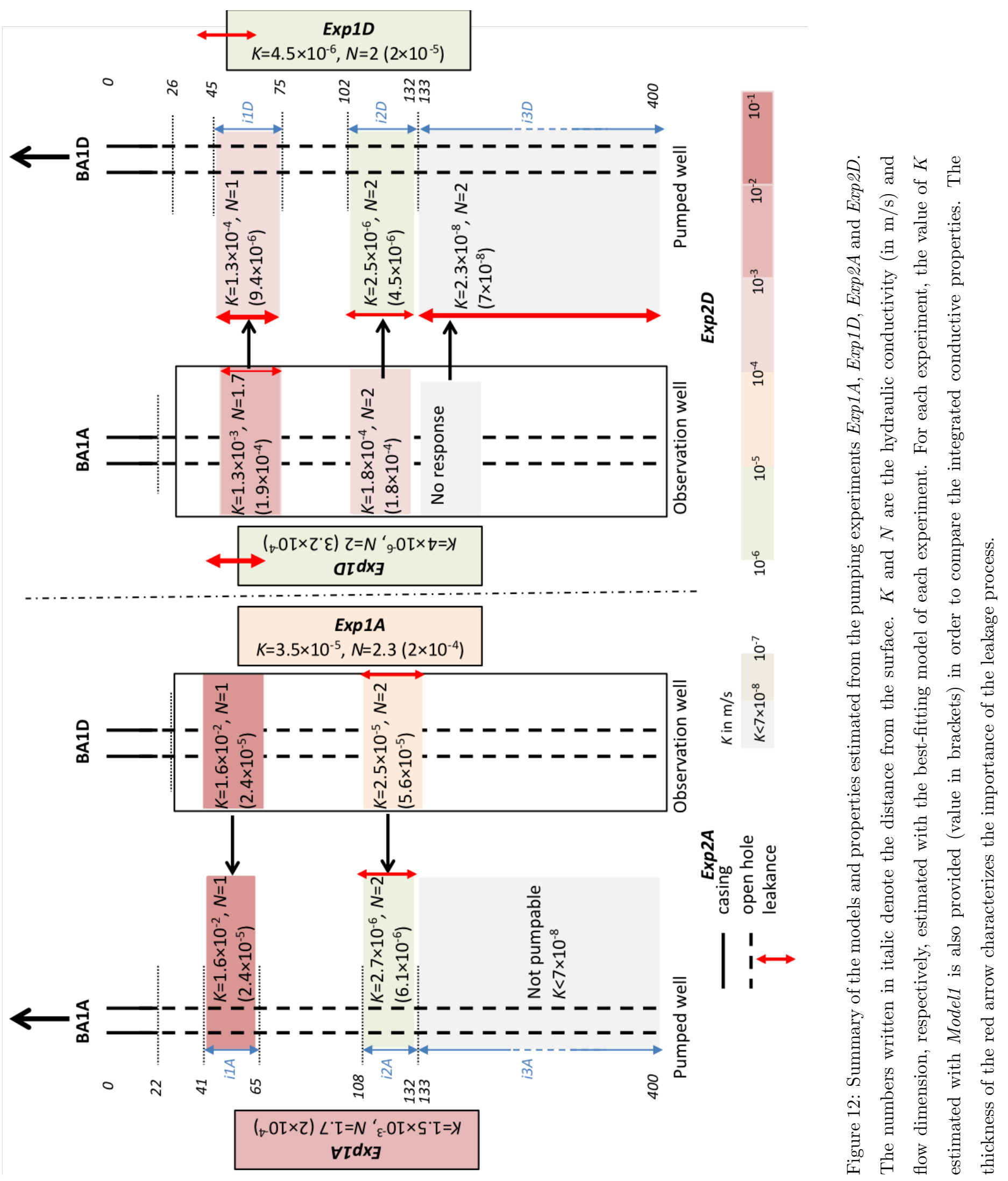


644 York

Eng. Said Al Habsi, Dr. Rashid Al Abri, Eng. Salim Al Khanbashi, Eng. Haider Ahmed Mohammed Alajmi, Mohsin Al Shukaili, Salim, Al Amri, and Ali Al Shukaili from the Ministry of Regional Municipalities and Water Resources for logistical and technical support during the borehole testing. We also thank Prof. Martin Stute and Prof. Amelia (Paukert) Vankeuren for experimental assistance, and Dr. Marguerite Godard for her helpful comments on the manuscript and for the edition of Figure 1. Funding for this study was provided by the International Continental Scientific Drilling Program to the Oman Drilling Project, and the Alfred P. Sloan Foundation (Grant 2014-301) and U.S. NSF (Grant NSF-EAR-1516300) to Columbia University, New 


\section{Appendix A. Additional data}

Vertical heterogeneities of boreholes BA1A and BA1D were investigated by measuring the temperature profiles in the boreholes (Figure A.13) and conducting flowmeter tests under ambient and forced hydraulic conditions (Figure A.14). The temperature profiles are obtained with the multi parameter probe ALT QL40 OCEAN, which allows measuring temperature between 0 and $50{ }^{\circ} \mathrm{C}$, and the flowmeter data are obtained with the heat pulse flowmeter Mount Sopris HFP-2293, which allows measuring flow rates between 0.1 to $4 \mathrm{~L} / \mathrm{min}$. The data obtained under forced hydraulic conditions were collected while pumping at a flow rate of 18.12 and $4.47 \mathrm{~L} / \mathrm{min}$ in boreholes BA1A and BA1D, respectively. The full temperature profiles show temperature anomalies for both boreholes above $61 \mathrm{~m}$ (Figure A.13a), and their enlargement between 115 and $155 \mathrm{~m}$ shows a temperature anomaly at depth 130-131 m in borehole BA1A (Figure A.13b). From the flowmeter data collected in borehole BA1A, we observe changes in the vertical flow rates at depth 22-29 $\mathrm{m}$ in Figure A.14 and at depth 33-39, 45-46 and 58-59 m in Figure A.14b. Finally, the flowmeter data collected in borehole BA1D and displayed in Figure A.14 show changes in the vertical flow rates at depth 26-27, 62-64 and 105-130 m. These conductive zones are reported in Table A.10 with the corresponding intervals that are considered for the packer experiments in order to characterize these zones. The isolated intervals are chosen such that they include the conductive zones and they are located at comparable positions for both boreholes.

While conducting the packer experiments, the pressure changes above and below the isolated intervals are monitored. These pressures, denoted 

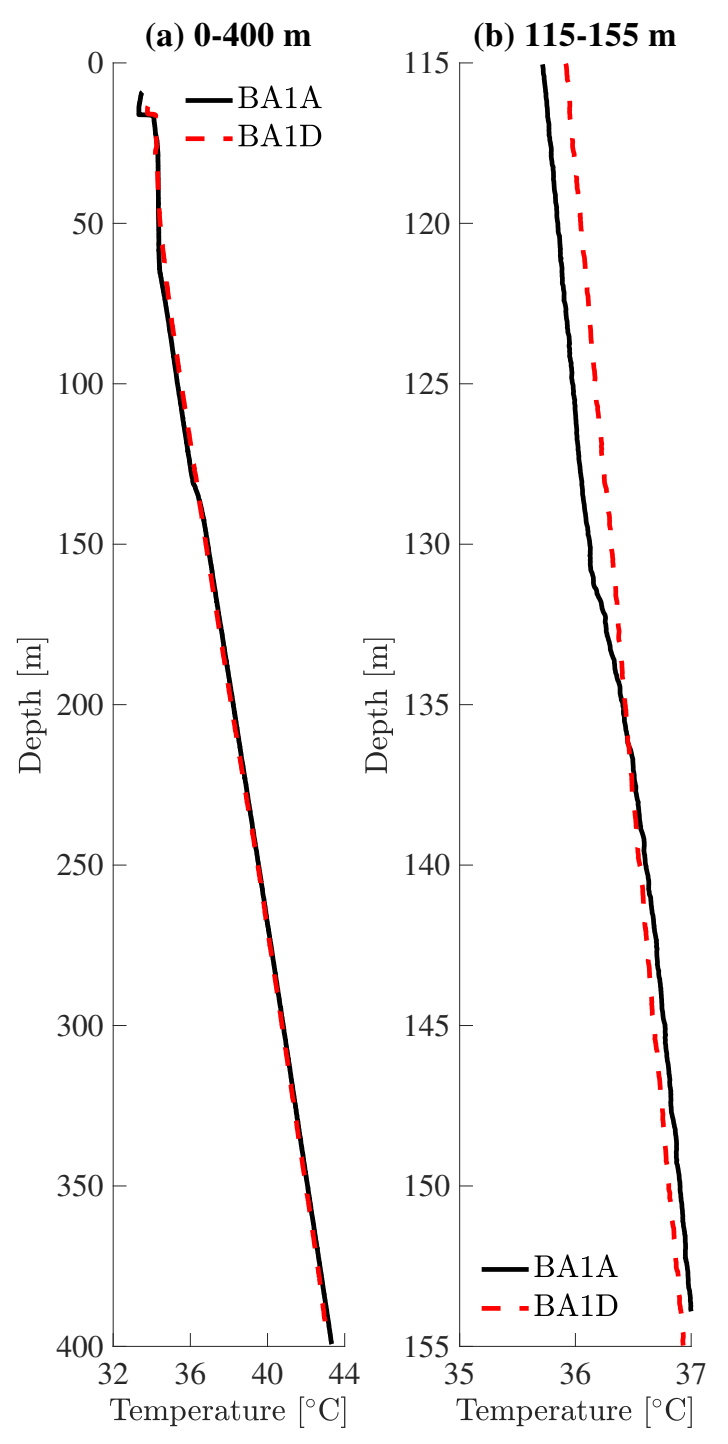

Figure A.13: Temperature profile in boreholes BA1A and BA1D (a) from 0 to $400 \mathrm{~m}$ and (b) from 115 to $155 \mathrm{~m}$ depth, showing an anomaly in temperature at depth 130-131 m in borehole BA1A. 
(a)

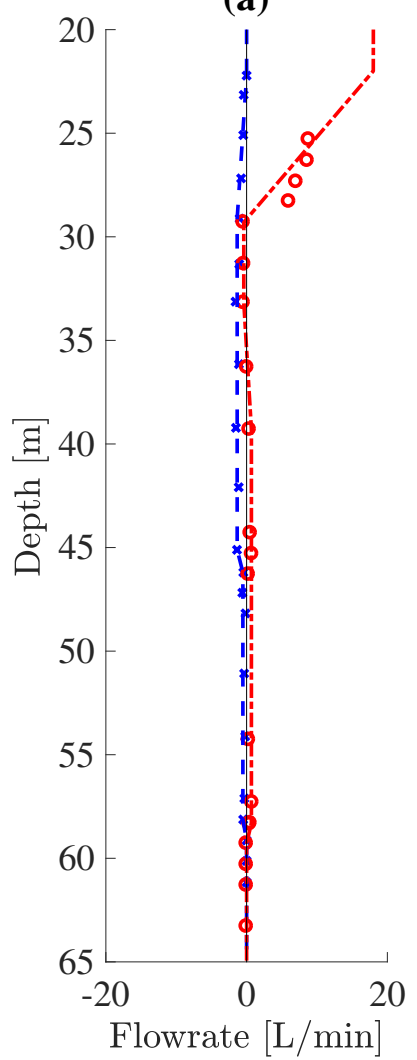

(b)

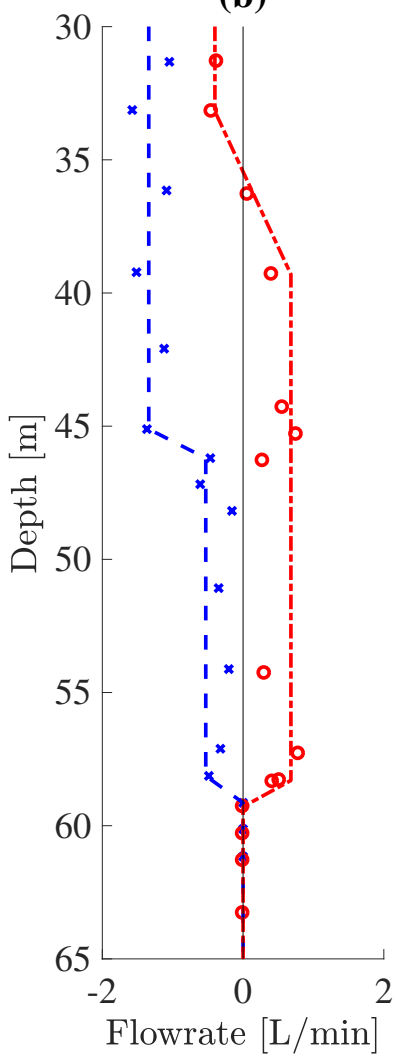

(c)

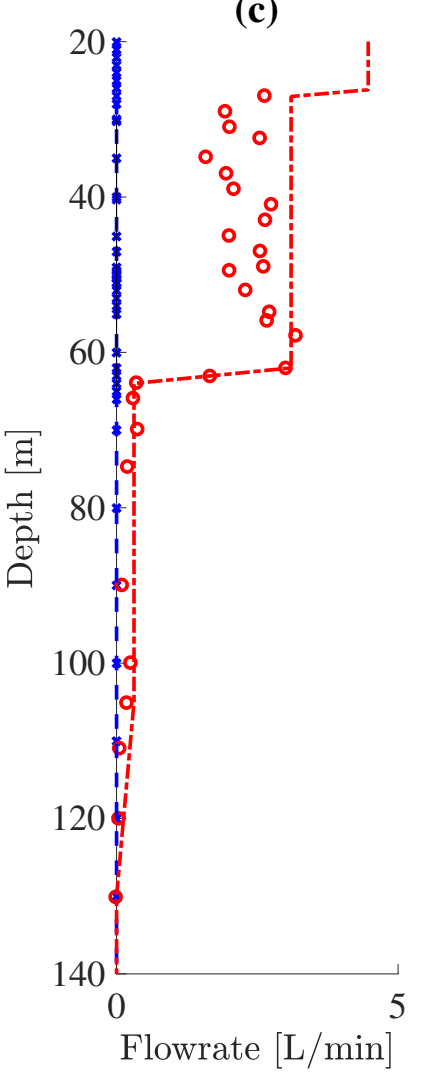

Figure A.14: Flowmeter data collected under ambient (blue crosses and dashed lines) and forced (red circles and dotted lines) hydraulic conditions in boreholes (a-b) BA1A and (c) BA1D. Symbols and (dashed and dotted) lines correspond to raw and interpreted data, respectively. The black line represent zero values of flowrate. (b) corresponds to a zoom-in of (a) for interpretation purpose. The values monitored below $65 \mathrm{~m}$ in (a-b) and below $140 \mathrm{~m}$ in (c) are null (and not shown).

$P_{1}$ (below) and $P_{3}$ (above), are reported in Figure A.15 for experiments Exp2A_i1A, Exp2A_i2A, Exp2D_i1D and Exp2D_i2D. The pressures are not shown for experiments Exp2A_i3A since the pumping could not be applied, and Exp2D_i3D because $P_{1}$ is not recorded for the interval located at the 


\begin{tabular}{l|cc|cc} 
Borehole & \multicolumn{2}{|c|}{ BA1A } & \multicolumn{2}{c}{ BA1D } \\
Packer tests & Exp2A_i1A & Exp2A_i2A & Exp2D_i1D & Exp2D_i2D \\
\hline Conductive zones & $45-46 ; 58-59$ & $130-131$ & $62-64$ & $105-130$ \\
Isolated intervals & $41-65$ & $108-132$ & $45-75$ & $102-132$
\end{tabular}

Table A.10: Conductive zones identified from the temperature profiles and flowmeter data presented in Figures A.13 and A.14 with the corresponding packer experiments and isolated intervals that are used to characterize the zones.

bottom of the borehole and $P_{3}$ displays changes smaller than $0.06 \mathrm{mH} 2 \mathrm{O}$ in this case.

As additional information, we also wish to provide the lithostratigraphy in boreholes BA1A and BA1D that is shown in Figure A.16. These lithological logs were obtained during drilling by describing drill cuttings for every meter drilled. The main bedrock lithologies are dunite and harzburgite, whereas gabbro is a minor rock type that forms centimeter to decimeter thick dikes. The alluvium on top of the bedrock is relatively thin with a thickness between 18 and $25 \mathrm{~m}$, followed by a relatively thick zone of dunites to a depth of 160 (BA1A) and $250 \mathrm{~m}$ (BA1D) below surface, respectively. Harzburgite is present in the deeper part of both holes. Both, the dunite and harzburgite are highly altered with serpentine (lizardite and chrysotile) and brucite being the dominant alteration minerals (Kelemen et al., 2020). All conductive zones, detected by flowmeter logging, are within the upper dunite section of the boreholes. 
(a) Exp2A_i1A

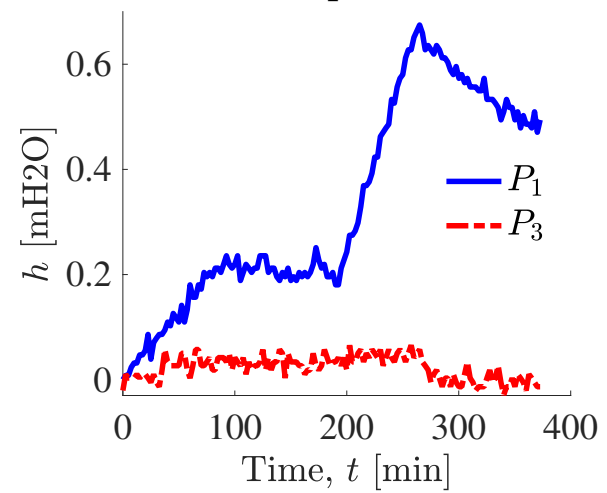

(c) Exp2D_i1D

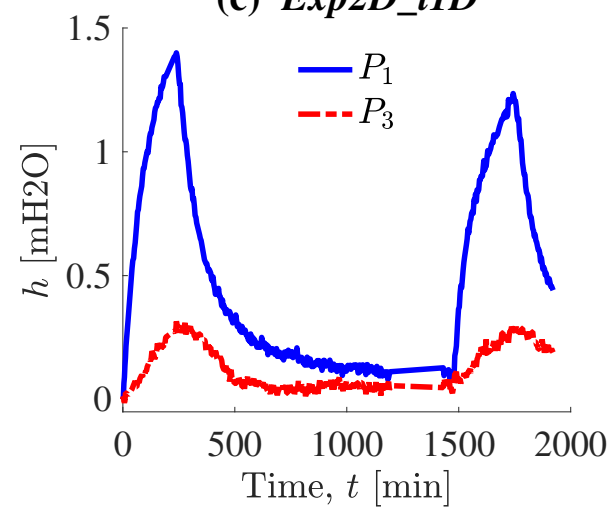

(b) Exp2A_i2A

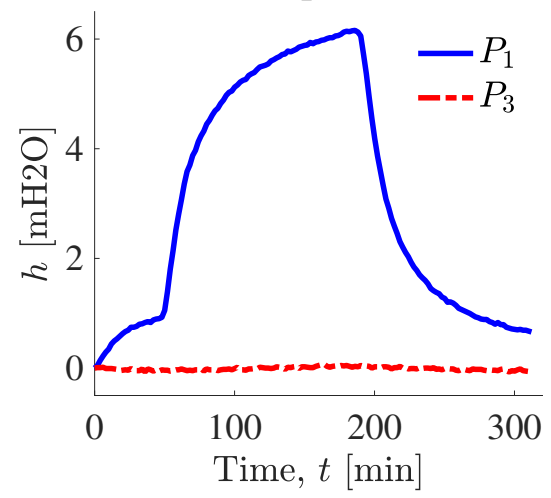

(d) Exp2D_i2D

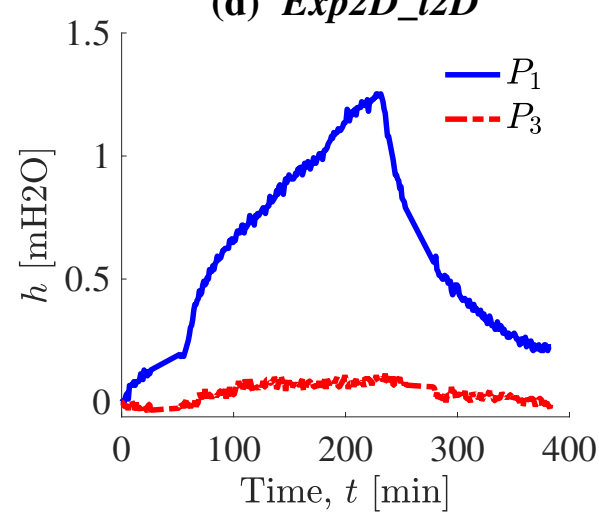

Figure A.15: Pressures $P_{1}$ (blue solid lines) and $P_{3}$ (red dotted lines) monitored below and above, respectively, the isolated interval during the packer experiments (a) Exp2A_i1A, (b) Exp2A_i2A, (c) Exp2D_i1D and (d) Exp2D_i2D.

\section{Appendix B. General model}

We wish here to formulate a model with non-integral flow dimension, vertical leakage, and transient pumping flow rates. To this end, we started from the analytical solution for transient radial flow in a fractal fractured aquifer with leakance presented in Hamm and Bidaux (1994), which combines the generalized radial flow model (Barker, 1988) with leakance (Hantush, 


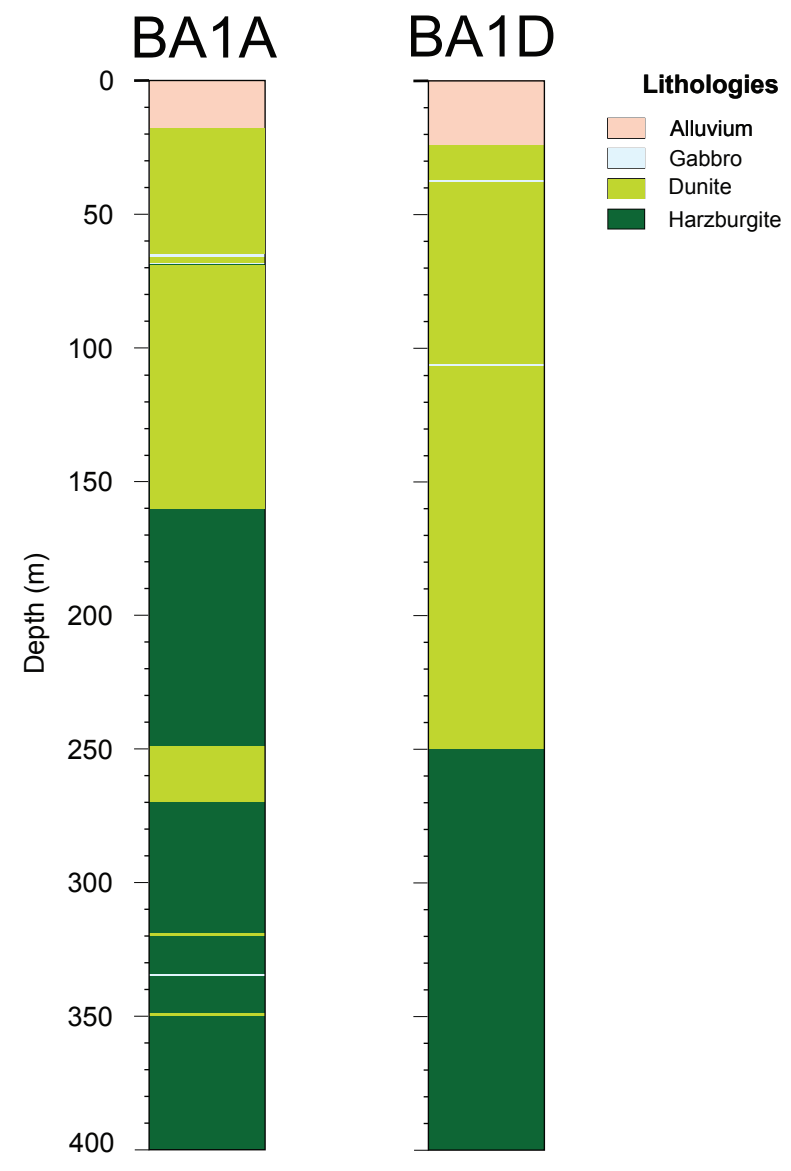

Figure A.16: Lithostratigraphic log of OmanDP holes BA1A and BA1D, showing the vertical distribution of the major lithologies.

695 1956), and extend it to time-dependent pumping flow rates and non-linear 696 skin effects. 
Let us consider the equations governing the drawdowns $h(r, t)[\mathrm{m}]$ in the aquifer and $h_{w}(t)[\mathrm{m}]$ in the pumping well

$$
S_{s} \frac{\partial h}{\partial t}=\frac{K}{r^{N-1}} \frac{\partial}{\partial r}\left(r^{N-1} \frac{\partial h}{\partial r}\right)-\frac{K}{B^{2}} h,
$$$$
h(t \leq 0)=0, \quad \lim _{r \rightarrow \infty} h=0,
$$

and

$$
\begin{gathered}
S_{w} \frac{\partial h_{w}}{\partial t}=G_{N}(b) r_{w}^{N-1} K\left[\frac{\partial h}{\partial r}\right]_{r=r_{w}}+Q, \\
h_{w}(t \leq 0)=0, \quad h_{w}=\left[h-r_{w} \sigma_{w} \frac{\partial h}{\partial r}\right]_{r=r_{w}}
\end{gathered}
$$

with

$$
G_{N}(b)=\frac{2 \pi^{N / 2} b^{3-N}}{\Gamma(N / 2)},
$$

$t[\mathrm{~s}]$ the time elapsed since the pumping starts, $r[\mathrm{~m}]$ the distance from the pumped well, $K\left[\mathrm{~m} \mathrm{~s}^{-1}\right]$ the hydraulic conductivity, $S_{s}\left[\mathrm{~m}^{-1}\right]$ the specific storage, $N[-]$ the flow dimension, $B[\mathrm{~m}]$ the leakage factor, $r_{w}[\mathrm{~m}]$ the pumping well exchange radius with the aquifer, $b[\mathrm{~m}]$ the pumping well ortho-radial extent, $S_{w}\left[\mathrm{~m}^{2}\right]$ the pumping well storage coefficient, $\sigma_{w}[-]$ the pumping well skin factor, and $Q\left[\mathrm{~m}^{3} \mathrm{~s}^{-1}\right]$ the pumping flow rate. A full description of these parameters is provided in Barker (1988), except for the parameter $B$ which is explained in Hantush (1956).

The solutions for $(\overline{B .1})$ and $(\overline{B .2})$ are expressed in the Laplace domain as

$$
\bar{h}=\frac{\bar{h}_{w} r^{\nu} \mathrm{K}_{\nu}(\gamma r)}{A} \quad \text { and } \quad \bar{h}_{w}=\frac{\bar{Q}(p) A}{A S_{w} p+A^{\prime}}
$$


728

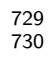

731

with $p$ the Laplace variable, $\bar{Q}$ the Laplace transform of the pumping flow rate, $\mathrm{K}_{\nu}$ the modified Bessel function of the second kind and order $\nu$,

$$
A=r_{w}^{\nu}\left[\mathrm{K}_{\nu}\left(\gamma r_{w}\right)+\sigma_{w} \gamma r_{w} \mathrm{~K}_{\nu-1}\left(\gamma r_{w}\right)\right]
$$

$$
A^{\prime}=G_{N}(b) r_{w}^{N / 2} K \gamma K_{\nu-1}\left(\gamma r_{w}\right)
$$

$$
\nu=1-N / 2
$$

$$
\text { and } \quad \gamma=\sqrt{\frac{p S_{s}}{K}+\frac{1}{B^{2}}} \text {. }
$$

Considering a pumping flow rate decreasing exponentially from $Q_{1}$ to $Q_{2}$ at time $t_{1}$ and $t_{2}$, respectively, the equation for $Q(t)$ is

$$
Q(t)=a \exp \left(-\frac{t}{d}\right)+c
$$

where the coefficients $a$ and $c$ are

$$
a=\left(Q_{1}-c\right) \exp \left(\frac{t_{1}}{d}\right) \text { and } c=\frac{Q_{2}-\delta Q_{1}}{1-\delta}
$$

with $\delta=\exp \left[\left(t_{1}-t_{2}\right) / d\right]$ and $d$ being a fitting coefficient that controls the decrease shape. The Laplace transform of $Q$ is

$$
\bar{Q}(p)=\frac{a}{p+1 / d}+\frac{c}{p} .
$$

The solution during the recovery period (i.e., $t>t_{2}$ ) is evaluated with the superposition method by subtracting to solutions (B.3) the drawdown values $h\left(r, t^{\prime}\right)$ and $h_{w}\left(t^{\prime}\right)$ obtained with the flow rate $Q^{\prime}\left(t^{\prime}\right)$, which is defined as $Q^{\prime}\left(t^{\prime}\right)=Q(t)$ and expressed as

$$
Q^{\prime}\left(t^{\prime}\right)=a^{\prime} \exp \left(-\frac{t^{\prime}}{d}\right)+c
$$


with $a^{\prime}=a \exp \left(-t_{2} / d\right)$ and $t^{\prime}=t-t_{2}$.

Finally, the solution (B.3) obtained in the Laplace domain is inverted to the time domain by using the Stehfest's algorithm (Stehfest, 1970). For step drawdown tests, non-linear skin effects (i.e., the skin factor depends on the flow rate (van Everdingen, 1953)) are taken into account by applying the superposition method presented in Lods and Gouze (2004). For a flow rate history $\left\{\left(t_{i}, Q_{i}\right), i=1, n\right\}$, where the rate $Q_{i}$ is applied between times $t_{i}$ and $t_{i+1}$, the superposed drawdown $h_{\text {sup }}$ at time $t\left(t_{i} \leq t<t_{i+1}\right)$ is

$$
h_{\text {sup }}(t)=\sum_{j=1}^{i-1}\left[h\left(t-t_{j}, Q_{j}\right)-h\left(t-t_{j+1}, Q_{j}\right)\right]+h\left(t-t_{i}, Q_{i}\right),
$$

where $h(t, Q)$ is the drawdown at time $t$ produced by a flow pulse $Q$ beginning at time zero.

\section{Appendix C. Interpretation method}

The pumping experiments are analyzed by estimating the hydraulic parameters that give the best fit between the data collected and several analytical models. These models rely on the analytical solution presented in Appendix B and are used to evaluate the properties and reveal the active processes that control the hydraulic responses of the studied system, as well as the flow geometry described by the flow dimension $N$ (Barker, 1988). With these definitions, we consider the four following models: (i) the reference cylindrical flow model without leakage (Model1) corresponding to solution (B.3) with $N=2$ and $1 / B^{2}=0$, (ii) the generalized radial flow model without leakage (Model2) corresponding to solution (B.3) with $1 \leq N \leq 3$, $N \neq 2$ and $1 / B^{2}=0$, (iii) the cylindrical flow model with leakage (Model3) 
corresponding to solution (B.3) with $N=2$ and $1 / B^{2}>0$, and (iv) the generalized radial flow model with leakage (Model4) corresponding to solution (B.3) without restrictions, except the cases $N=2$ and $1 / B^{2}=0$ which correspond to the previous domains. For all these models, the following assumptions and statements are considered:

(i) The ortho-radial extent $b$ in $(\overline{B .3})$ is set such that the exchange area between the pumped borehole and the aquifer is constant and equal to that for $N=2$ and $b=1 \mathrm{~m}$, knowing that $b$ corresponds to the (unknown) aquifer thickness in this case.

(ii) The correction of head data for regional trend associated with transient head changes is assumed to be not necessary because the long-term monitoring performed during the year preceding the tests shows negligible variations at the scale of the tests (decrease smaller than $0.07 \mathrm{~mm} / \mathrm{h}$ ).

(iii) The wellbore storage coefficient is apriori set to $10^{-12} \mathrm{~m}^{2}$ for the packer tests, which corresponds to a negligible pumping chamber deformation, while it is apriori set to the free surface area of the pumping well for open borehole pumping tests.

(iv) The flowrate is assumed to be either constant or exponentially decreasing during each pump step.

The parameter estimation is done by considering that (i) the wellbore storage coefficient $S_{w}$ and the skin factor $\sigma_{w}$ mostly impact the drawdown data collected in the pumped borehole such that $S_{w}$ is evaluated by fitting the shape of the beginning of the corresponding curve and $\sigma_{w}$ the amplitude of this curve, and (ii) the aquifer diffusivity value $K / S_{s}$, hydraulic conductivity $K$, and leakage factor $B$ are evaluated by fitting the response delay 
of the observation well, the slopes of the drawdown curves collected in the pumped and observation wells, and the amplitude of these curves, respectively. When a common model reproducing the data collected in both the pumped and observation boreholes cannot be found, we define a model for each borehole resulting in estimated properties and parameters associated with each borehole.

These estimations are systematically performed with the following procedure until obtaining a satisfying fit between the collected data and the considered model. First, the standard cylindrical flow model without leakage (Model1) is considered and the resulting hydraulic property values are used for tests comparison. Then, other flow geometries without leakage are explored (Model2), and finally the impact of leakage is analyzed with cylindrical flow (Model3) and generalized radial flow (Model4). The best fit that is obtained manually is verified, and improved if needed, with an automatic fitting tool. This tool, which relies on the gradient algorithm with random multistart method, is used to solve the corresponding least square problem with weights applied to critical parts of the head data. In particular, additional weights are applied on the beginning of the drawdown curve in the observation well, the end of the drawdown and recovery curves in both the pumped and observation wells, as well as the end of the drawdown steps when considering step-by-step flow rates. The beginning of the drawdown curve in the observation well is carefully fitted because it allows to adjust accurately the diffusivity value.

Finally, we also provide the transmissivity values estimated from Theis' solution with the standard recovery interpretation method (Kruseman and 
de Ridder, 1990) when the conditions ensuring the reliability of this solution hold. These conditions, which correspond to constant pumping flow rate, negligible wellbore storage and skin effects, and validity of the logaritmic Jacob's approximation, are fulfilled by working on the end of well-developed recovery curves. Note that the wellbore storage effect is negligible for packer tests and that Theis's solution is a restriction of Model1 to a constant flowrate with no pumping well storage and no skin effect.

\section{References}

Abbate, E., Bortolotti, V., Passerini, P., Principi, G., 1985. The rhythm of phanerozoic ophiolites. Ofioliti 10, 109-138.

Ahmed, T., Meehan, N., 2011. Advanced Reservoir Management and Engineering. Elsevier Science.

Audouin, O., Bodin, J., Porel, G., Bourbiaux, B., 2008. Flowpath structure in a limestone aquifer: multi-borehole logging investigations at the hydrogeological experimental site of Poitiers, France. Hydrogeology Journal 16, 939-950. doi:10.1007/s10040-008-0275-4.

Bailey, E., 1981. Geologic map of the muscat-ibra area, sultanate of oman. J. Geophys. Res. 86B4,, pocket map, 1:100,000,

Barker, J., 1988. A generalized radial flow model for hydraulic tests in fractured rock. Water Resources Research 24, 1796-1804. doi:10.1029/ WR024i010p01796. 
Bear, J., 1979. Hydraulics of Groundwater. McGraw-Hill series in water resources and environmental engineering, McGraw-Hill International Book Co.

Boronina, A., Balderer, W., Renard, P., Stichler, W., 2005. Study of stable isotopes in the Kouris catchment (Cyprus) for the description of the regional groundwater flow. Journal of Hydrology 308, 214-226. doi:10.1016/j·jhydrol.2004.11.001.

Boronina, A., Renard, P., Balderer, W., Christodoulides, A., 2003. Groundwater resources in the Kouris catchment (Cyprus): data analysis and numerical modelling. Journal of Hydrology 271, 130-149. doi:10.1016/ S0022-1694(02)00322-0.

Cihan, A., Zhou, Q., Birkholzer, J.T., 2011. Analytical solutions for pressure perturbation and fluid leakage through aquitards and wells in multilayeredaquifer systems. Water Resources Research 47, W10504. doi:10.1029/ 2011WR010721.

Day-Lewis, F.D., Johnson, C.D., Paillet, F.L., Halford, K.J., 2011. A computer program for Flow-Log Analysis of Single Holes (FLASH). Ground Water 49, 926-931. doi:10.1111/j.1745-6584.2011.00798.x.

Dewandel, B., Lachassagne, P., Boudier, F., Al-Hattali, S., Ladouche, B., Pinault, J.L., Al-Suleimani, Z., 2005. A conceptual hydrogeological model of ophiolite hard-rock aquifers in Oman based on a multiscale and a multidisciplinary approach. Hydrogeology Journal 13, 708-726. doi:10.1007/s10040-005-0449-2. 
Dewandel, B., Lachassagne, P., Qatan, A., 2004. Spatial measurements of stream baseflow, a relevant method for aquifer characterization and permeability evaluation. application to a hard-rock aquifer, the oman ophiolite. Hydrological Processes 18, 3391-3400. doi:10.1002/hyp.1502.

Einaudi, F., Pezard, P., Cochem, J.J., Coulon, C., Laverne, C., Godard, M., 2000. Petrography, geochemistry and physical properties of a continuous extrusive section from the hilti massif, oman ophiolite. Marine Geophys. Res. 21, 387-407.

van Everdingen, A., 1953. The skin effect and its influence on the productive capacity of a well. Trans. AIME 198, 171-176.

Hamm, S.Y., Bidaux, P., 1994. Transient flow with fractal geometry and leakage: theory and application. C.R. Académie des Sciences, Paris, 318, série II, $\mathrm{n}^{\circ} 2,227-233$.

Hamm, S.Y., Bidaux, P., 1996. Dual-porosity fractal models for transient flow analysis in fissured rocks. Water Resources Research 32, 2733-2745. doi:10.1029/96WR01464.

Hantush, M.S., 1956. Analysis of data from pumping tests in leaky aquifers. 口 Eos, Transactions American Geophysical Union 37, 702-714. doi:10.1029/ TR037i006p00702.

Jacob, C., 1947. Drawdown test to determine effective radius of an artesian well. Transactions of the Proceedings of the American Society Civil Engineering 112, 1047-1064. 
Jeanpert, J., Iseppi, M., Adler, P.M., Genthon, P., Sevin, B., Thovert, J.F., Dewandel, B., Join, J.L., 2019. Fracture controlled permeability of ultramafic basement aquifers. Inferences from the Koniambo massif, New Caledonia. Engineering Geology 256, 67-83. doi:10.1016/j .enggeo.2019.05. 006.

Kelemen, P., Matter, J., Teagle, D., Coggon, J., the Oman Drilling Project Science Team, 2020. Proceedings of the Oman Drilling Project: College Station. doi:10.14379/0manDP.proc.2020.

Kruseman, G.P., de Ridder, N.A., 1990. Analysis and evaluation of pumping test data. ILRI publication, International Institute for Land Reclamation and Improvement.

Le Borgne, T., Bour, O., de Dreuzy, J.R., Davy, P., Touchard, F., 2004. Equivalent mean flow models for fractured aquifers: Insights from a pumping tests scaling interpretation. Water Resources Research 40. doi:10.1029/2003WR002436.

Le Borgne, T., Bour, O., Riley, M.S., Gouze, P., Pezard, P.A., Belghoul, A., Lods, G., Le Provost, R., Greswell, R.B., Ellis, P.A., Isakov, E., Last, B.J., 2007. Comparison of alternative methodologies for identifying and characterizing preferential flow paths in heterogeneous aquifers. Journal of Hydrology 345, 134-148. doi:10.1016/j j jhydro1.2007.07.007.

Lods, G., Gouze, P., 2004. WTFM, software for well test analysis in fractured media combining fractional flow with double porosity and leakance ap- 
proaches. Computers \& Geosciences 30, 937-947. doi:10.1016/j.cageo. 2004.06 .003 .

Lods, G., Gouze, P., 2008. A generalized solution for transient radial flow in hierarchical multifractal fractured aquifers. Water Resources Research 44. doi:10.1029/2008WR007125.

Maury, S., Balaji, S., 2014. Geoelectrical method in the investigation of groundwater resource and related issues in Ophiolite and Flysch formations of Port Blair, Andaman Island, India. Environmental Earth Sciences 71, 183-199. doi:10.1007/s12665-013-2423-y.

Miller, H.M., Matter, J.M., Kelemen, P., Ellison, E.T., Conrad, M.E., Fierer, N., Ruchala, T., Tominaga, M., Templeton, A.S., 2016. Modern water/rock reactions in Oman hyperalkaline peridotite aquifers and implications for microbial habitability. Geochimica et Cosmochimica Acta 179, 217-241. doi:10.1016/j.gca.2016.01.033.

Nicolas, A., Boudier, F., Ildefonse, B., Ball, E., 2000. Accretion of Oman and United Arab Emirates ophiolite - Discussion of a new structural map. Marine Geophysical Researches 21, 147-180. doi:10.1023/A:1026769727917.

Nikic, Z., Sreckovic-Batocanin, D., Burazer, M., Ristic, R., Papic, P., Nikolic, V., 2013. A conceptual model of mildly alkaline water discharging from the Zlatibor ultramafic massif, western Serbia. Hydrogeology Journal 21, 1147-1163. doi:10.1007/s10040-013-0983-2.

Noël, J., Godard, M., Oliot, E., Célérier, B., Maillard, Y., Kelemen, P.B., Michibayashi, K., 2018. Overview of lithology and structure of a mantle 
section of the Oman Ophiolite (BA active alteration sites, Oman Drilling Project): an integrated field mapping and boreholes imaging study, American Geophysical Union Fall Meeting, Washington, D.C. 10-14 Dec.

Paukert, A.N., Matter, J.M., Kelemen, P.B., Shock, E.L., Havig, J.R., 2012. Reaction path modeling of enhanced in situ CO2 mineralization for carbon sequestration in the peridotite of the Samail Ophiolite, Sultanate of Oman. Chemical Geology 330-331, 86-100. doi:10.1016/j.chemgeo.2012.08. 013.

Paukert-Vankeuren, A.N., Matter, J.M., Stute, M., Kelemen, P.B., 2019. Multitracer determination of apparent groundwater ages in peridotite aquifers within the Samail ophiolite, Sultanate of Oman. Earth and Planetary Science Letters 516, 37-48. doi:10.1016/j.epsl.2019.03.007.

Rempfert, K.R., Miller, H.M., Bompard, N., Nothaft, D., Matter, J.M., Kelemen, P., Fierer, N., Templeton, A.S., 2017. Geological and Geochemical Controls on Subsurface Microbial Life in the Samail Ophiolite, Oman. Frontiers in Microbiology 8, 56. doi:10.3389/fmicb.2017.00056.

Rorabaugh, M., 1953. Graphical and theoretical analysis of step-drawdown test of artesian well. Proceedings of the American Society Civil Engineering $79,23$.

Segadelli, S., Vescovi, P., Chelli, A., Petrella, E., De Nardo, M.T., Gargini, A., Celico, F., 2017b. Hydrogeological mapping of heterogeneous and multi-layered ophiolitic aquifers (Mountain Prinzera, northern Apennines, 
961 Italy). Journal of Maps 13, 737-746. doi:10.1080/17445647.2017. $962 \quad 1376228$.

$977 \quad 00577 . \mathrm{x}$

978 $00577 . x$

Segadelli, S., Vescovi, P., Ogata, K., Chelli, A., Zanini, A., Boschetti, T., Petrella, E., Toscani, L., Gargini, A., Celico, F., 2017a. A conceptual hydrogeological model of ophiolitic aquifers (serpentinised peridotite): The test example of Mt. Prinzera (Northern Italy). Hydrological Processes 31, 1058-1073. doi:10.1002/hyp.11090.

Stehfest, H., 1970. Algorithm 368: Numerical inversion of laplace transform. Communication of the ACM 13, 47-49.

Vacquand, C., Deville, E., Beaumont, V., Guyot, F., Sissmann, O., Pillot, D., Arcilla, C., Prinzhofer, A., 2018. Reduced gas seepages in ophiolitic complexes: Evidences for multiple origins of the H-2-CH4N-2 gas mixtures. Geochimica et Cosmochimica Acta 223, 437-461. doi:10.1016/j.gca.2017.12.018.

Verbovšek, T., 2009. Influences of aquifer properties on flow dimensions in dolomites. Groundwater 47, 660-668. doi:10.1111/j.1745-6584.2009.

Yeh, H.D., Chang, Y.C., 2013. Recent advances in modeling of well hy979 draulics. Advances in Water Resources 51, 27-51. doi:10.1016/j. advwatres.2012.03.006. 